\title{
Nrf2 pathway activation contributes to anti-fibrosis effects of ginsenoside Rg1 in a rat model of alcohol- and $\mathrm{CCl}_{4}$-induced hepatic fibrosis
}

\author{
Jian-ping $\mathrm{LI}^{1}$, Yan $\mathrm{GAO}^{1}$, Shi-feng $\mathrm{CHU}^{1}$, Zhao ZHANG ${ }^{1}$, Cong-yuan $\mathrm{XIA}^{1}$, Zheng MOU ${ }^{1}$, Xiu-yun SONG ${ }^{1}$, Wen-bin $\mathrm{HE}^{1,2}$, \\ Xiao-feng $\mathrm{GUO}^{2}$, Nai-hong $\mathrm{CHEN}^{1, *}$ \\ ${ }^{1}$ State Key of Laboratory Bioactive Substances and Functions of Natural Medicines, Department of Pharmacology, Institute of Materia \\ Medica, Chinese Academy of Medical Sciences and Peking Union Medical College, Beijing 100050, China; ${ }^{2}$ Shanxi University of \\ Traditional Chinese Medicine, Taiyuan 030024, China
}

Aim: To investigate the anti-fibrosis effects of ginsenoside Rg1 on alcohol- and $\mathrm{CCl}_{4}$-induced hepatic fibrosis in rats and to explore the mechanisms of the effects.

Methods: Rats were given $6 \%$ alcohol in water and injected with $\mathrm{CCl}_{4}(2 \mathrm{~mL} / \mathrm{kg}, \mathrm{sc}$ ) twice a week for 8 weeks. Rg1 (10, 20 and $40 \mathrm{mg} / \mathrm{kg}$ per day, po) was administered in the last 2 weeks. Hepatic fibrosis was determined by measuring serum biochemical parameters, HE staining, Masson's trichromic staining, and hydroxyproline and $\alpha$-SMA immunohistochemical staining of liver tissues. The activities of antioxidant enzymes, lipid peroxidation, and Nrf2 signaling pathway-related proteins (Nrf2, Ho-1 and Nqo1) in liver tissues were analyzed. Cultured hepatic stellate cells (HSCs) of rats were prepared for in vitro studies.

Results: In the alcohol- and $\mathrm{CCl}_{4}$-treated rats, Rg1 administration dose-dependently suppressed the marked increases of serum ALT, AST, LDH and ALP levels, inhibited liver inflammation and HSC activation and reduced liver fibrosis scores. Rg1 significantly increased the activities of antioxidant enzymes (SOD, GSH-Px and CAT) and reduced MDA levels in liver tissues. Furthermore, Rg1 significantly increased the expression and nuclear translocation of Nrf2 that regulated the expression of many antioxidant enzymes. Treatment of the cultured $\mathrm{HSCs}$ with Rg1 $(1 \mu \mathrm{mol} / \mathrm{L})$ induced $\mathrm{Nrf2}$ translocation, and suppressed $\mathrm{CCl}_{4}$-induced cell proliferation, reversed $\mathrm{CCl}_{4}$. induced changes in MDA, GPX, PCIII and HA contents in the supernatant fluid and $\alpha$-SMA expression in the cells. Knockdown of Nrf2 gene diminished these actions of Rg1 in $\mathrm{CCl}_{4}$-treated $\mathrm{HSCs}$ in vitro.

Conclusion: Rg1 exerts protective effects in a rat model of alcohol- and $\mathrm{CCl}_{4}$-induced hepatic fibrosis via promoting the nuclear translocation of Nrf2 and expression of antioxidant enzymes.

Keywords: ginseng; ginsenoside; Rg1; hepatic fibrosis; hepatic stellate cells; alcohol; $\mathrm{CCl}_{4}$; antioxidant enzymes; Nrf2 pathway

Acta Pharmacologica Sinica (2014) 35: 1031-1044; doi: 10.1038/aps.2014.41; published online 30 Jun 2014

\section{Introduction}

Hepatic fibrosis, a pathological outcome of the wound-healing response of the liver to repeated injury, and its end stage, cirrhosis, which is associated with an increased risk of liver failure, portal hypertension and liver cancer ${ }^{[1]}$, are of great concern worldwide because of the associated high morbidity and mortality ${ }^{[2-4]}$. Hepatic fibrosis results from an imbalance between extracellular matrix (ECM) synthesis and degradation which causes accumulation of ECM deposition. The activation of hepatic stellate cells (HSCs) plays a crucial role in the pathogenesis of hepatic fibrosis ${ }^{[5]}$. Activated HSCs could transform

\footnotetext{
* To whom correspondence should be addressed.

E-mail chennh@imm.ac.cn

Received 2014-01-02 Accepted 2014-04-11
}

to myofibroblast-like cells, expressing a-smooth muscle actin (a-SMA) and secreting ECM composed of various proteoglycans and proteins.

Reactive oxygen species (ROS) play an important role in the activation of HSCs, and a review emphasized that ROS contributes to both onset and progression of liver fibrosis ${ }^{[6]} \cdot \mathrm{CCl}_{4}$ is a widely used hepatoxin for animal models of liver fibrosis. It can be activated to trichloromethyl radical $\left(\cdot \mathrm{CCl}_{3}\right)$ and trichloromethyl peroxyradical $\left(\cdot \mathrm{OOCCl}_{3}\right)$ by $\mathrm{CYP} 450$ in the liver and stimulates Kupffer cells to produce ROS, which damage the liver ${ }^{[7,8]}$. In addition to the induction of oxidative stress, alcohol may upregulate the activity of P450 2E1 (CYP2E1) which catalyzes the conversion of $\mathrm{CCl}_{4}$ into $\mathrm{CCl}_{3}{ }^{[9,10]}$. The combination of the two hepatotoxins will accelerate the ROS damage. 
Antioxidant enzymes such as superoxide dismutase (SOD), glutathione peroxidase (GSH-Px) and catalase (CAT) have an important role in the elimination of ROS. The upregulation of many antioxidant enzymes in the liver is mediated by Nrf2. Several studies have shown that Nrf2 plays a protective role in $\mathrm{CCl}_{4}$-induced liver fibrosis by regulating the antioxidant enzyme activity and the expression of down-stream genes ${ }^{[11-13]}$.

Ginseng, the root of Panax ginseng CA Meyer, has been a key component in traditional Chinese medicine for more than 1000 years $^{[14]}$. The traditional beneficial effects of ginseng are replenishment of vital energy, longevity and mood elevation $^{[15]}$. The molecular constituents responsible for the action of ginseng are ginsenosides, among which, Rg1 is the most abundant and active ingredient of $P$ ginseng ${ }^{[14,16]}$. Several studies have shown that Rg1 or ginseng extract has a liver protective effect ${ }^{[16-22]}$. These findings strongly indicated that Rg1 is a potent antifibrotic agent.

The aim of the present study was to investigate the antifibrotic effects of $\mathrm{Rg} 1$ on alcohol- and $\mathrm{CCl}_{4}$-induced hepatic fibrosis in rats. We demonstrate that Rg1 inhibits hepatic inflammation and HSC activation in the pathogenesis of hepatic fibrosis. Rg1 effectively protects against alcohol- and $\mathrm{CCl}_{4}$-induced hepatic-fibrosis, of which the mechanism is related to the activation of Nrf2 pathway.

\section{Materials and methods}

\section{Chemicals and reagents}

Rg1 (HPLC 98\%) was obtained from Jilin University (Jilin, China). Bicyclol tablets were obtained from Beijing Union Pharmaceutical Factory (Beijing, China). $\mathrm{CCl}_{4}$ was purchased from Beijing Chemical Works (Beijing, China); olive oil was obtained from WILMAR Edible oils BV (Shenzhen, China).

Anti-HO-1, anti-NQO1, Nrf2, and a-smooth muscle actin (a-SMA) antibodies were purchased from Santa Cruz Biotechnology (Santa Cruz, CA, USA). The SOD antibody was obtained from Sigma-Aldrich (Sigma, MO, USA). Histone H3 antibody was obtained from Millipore (Boston, MA, USA). Enhanced chemiluminescent (ECL) substrate was obtained from Applygen Technologies Inc (Beijing, China).

\section{Animals experimental design}

Seven-week-old male Wistar rats weighing 200-220 g (SPF Experimental Animal's Science and Technology Co, Ltd, Beijing, China) were housed under standard environmental conditions and allowed free access to a commercial standard rodent diet and water ad libitum. The rats were maintained under constant conditions $\left(23 \pm 2{ }^{\circ} \mathrm{C}, 55 \% \pm 5 \%\right.$ humidity and $12 \mathrm{~h}$ light-dark cycle) in an air-conditioned room. All animals were handled in accordance with the standards established in the Guide for the Care and Use of Laboratory Animals published by the Institute of Laboratory Animal Resources of the National Research Council (United States) and approved by the Animal Care Committee of the Peking Union Medical College and the Chinese Academy of Medical Sciences.

Animals were randomly divided into three main groups: group A, group B and group C.
Group A had six small groups with six to ten rats per group as follows: group 1, control; group 2, $\mathrm{CCl}_{4}$ group; group 3, $\mathrm{CCl}_{4}$ plus Rg1-10 mg/kg; group 4, $\mathrm{CCl}_{4}$ plus $\mathrm{Rg} 1-20 \mathrm{mg} / \mathrm{kg}$; group 5, $\mathrm{CCl}_{4}$ plus $\mathrm{Rg} 1-40 \mathrm{mg} / \mathrm{kg}$; and group 6, $\mathrm{CCl}_{4}$ plus Bicyclol $200 \mathrm{mg} / \mathrm{kg}$. Rg1 and Bicyclol were prepared in a vehicle (double distilled water, $\mathrm{DDW}$ ), and $50 \% \mathrm{CCl}_{4}$ was dissolved in olive oil. Group 1 was treated subcutaneously with olive oil, and groups 2-6 were treated subcutaneously with $50 \% \mathrm{CCl}_{4}$ at a dose of $2 \mathrm{~mL} / \mathrm{kg}$ of body weight twice a week for 8 weeks. Six weeks after treatment, group 1 was administered the vehicle, and groups 2-6 were administered Rg1 or Bicyclol every day for $14 \mathrm{~d}$. Group 1 was given normal water, and groups 2-6 were given $6 \%(v / v)$ alcohol in water during the entire experiment.

The setup of group B was same to group A except for the $\mathrm{CCl}_{4}$ treatment. Group B had six sub-groups with 10 rats per group as follows: group 1, control; group 2, alcohol water group; group 3, Rg1-10 mg/kg; group 4, Rg1-20 mg/kg; group 5, Rg1-40 mg/kg; and group 6, Bicyclol $200 \mathrm{mg} / \mathrm{kg}$. Six weeks after treatment with $6 \%(v / v)$ alcohol water, group 1 was administered vehicle, and groups 2-6 were administered Rg1 or Bicyclol every day for $14 \mathrm{~d}$. Group 1 was given normal water, and groups 2-6 were given $6 \%(v / v)$ alcohol water during the entire experiment.

Group C had two sub-groups with 10 rats per group as follows: group 1, control; group 2, Rg1-40 mg/kg group. Group 1 was treated with DDW and group 2 with Rg1 orally once daily for $14 \mathrm{~d}$. All groups were given normal water.

\section{Liver functions evaluation}

Blood samples were obtained $72 \mathrm{~h}$ after the last $\mathrm{CCl}_{4}$ injection from the postcaval vein after the animals had been anaesthetized with ether. Serum alanine aminotransferase (ALT), aspartate aminotransferase (AST), lactate dehydrogenase (LDH) and alkaline phosphatase (ALP) were measured by an automatic biochemistry analyzer (TBA-40FR, TOSHIBA, Japan).

\section{Histopathological examination and immunohistochemistry}

Excised livers were fixed in $4 \%$ buffered paraformaldehyde for $24 \mathrm{~h}$, embedded in paraffin, and sectioned. Sections were cut into 4- $\mu$ m-thick sections and stained with hematoxylineosin (H\&E), Masson's trichrome and immunohistochemistry (a-SMA) procedure. To evaluate the histopathological changes, the stained tissue samples were examined under a light microscope. An arbitrary scope was given to each microscopic field viewed at magnifications of $\times 40-200$. At least 10 fields were scored per liver section to obtain the mean value. The scoring system for $\mathrm{CCl}_{4}$ chronic changes of hepatic inflammation, balloon degeneration and fibrosis were evaluated according to a score proposed by Thompson ${ }^{[23]}$. The scores of hepatic inflammation are as follows: Score 0: Absent; Score 1: Small amount of cells present at the junction of the necrotic zone; Score 2: Normal amount of cells present; Score 3: Predominantly neutrophils present; Score 4: Predominantly mononucleic cells present. Fibrosis extent was graded as: 
Score 0: Absent; Score 1: Thin septa present; Score 2: Thin septa present linking hepatic veins; Score 3: Broad/well-developed septa; Score 4: Cirrhosis. All specimens were scored by three pathologists, who were blinded to the scoring of the other pathologists. The results were analyzed with SPSS 13.0 using a nonparametric ranking analysis (Kruskal-Wallis test).

\section{Real-time quantitative polymerase chain reaction (qPCR) analysis}

Total RNA from liver samples was extracted with TRIzol (Invitrogen, USA). The expression of cytochrome P450 2E1 (CYP2E1) mRNA was analyzed by qPCR. The primers were as follows: CYP2E1 sense: 5'-GCTGTCAAGGAGGTGCTACT-3'; antisense: 5'-CCAGTCACGGAG GATACTTAGG-3'. GAPDH sense: 5'-GGTGAAGGTCGGTGTGAACG-3'; antisense: 5'-CTCGCTCCTGGAAGATGGTG -3'. The reaction conditions were: $95^{\circ} \mathrm{C}$ for $60 \mathrm{~s}$, then 40 cycles of $15 \mathrm{~s}$ at $95^{\circ} \mathrm{C}, 15 \mathrm{~s}$ at $59^{\circ} \mathrm{C}$, and $45 \mathrm{~s}$ at $72^{\circ} \mathrm{C}$ for extension. The results were normalized to the mRNA of the housekeeping gene GAPDH as an internal control and are presented as relative mRNA levels.

\section{Alcohol dehydrogenase (ADH) activity in liver tissues}

A $10 \%$ liver homogenate was used for the determination of the levels of ADH activities in liver tissues. ADH activity was detected colorimetrically with UV-visible spectrophotometer using commercial kits (Nanjing Jian Cheng Bioengineering Institute, Nanjing, China) according to the manufacturer's protocol.

\section{Assay of hydroxyproline in liver tissues}

Hepatic hydroxyproline content was measured using a commercial kit (Nanjing Jian Cheng Bioengineering Institute, Nanjing, China) according to the manufacturer's instructions. Briefly, $100 \mathrm{mg}$ of liver was hydrolyzed by alkali at $95^{\circ} \mathrm{C}$ for $20 \mathrm{~min}$. After cooling in water, the $\mathrm{pH}$ was adjusted to 6.0-6.8. A total of $10 \mathrm{~mL}$ double-distilled water was added to each tube, mixed with powdered activated carbon, and centrifuged at $1100 \times g$ for $10 \mathrm{~min}$. After combining with the designated reagents and a $15 \mathrm{~min}$ incubation at $60^{\circ} \mathrm{C}$ for 15 min, the mixture was centrifuged at $3500 \mathrm{r} / \mathrm{min}$ for $10 \mathrm{~min}$. The absorbance of the supernatant was read at $550 \mathrm{~nm}$. The hydroxyproline content in each sample was determined from a standard and was expressed as micrograms per gram of wet weight $(\mu \mathrm{g} / \mathrm{g})$.

\section{Lipid peroxidation assessment}

A $10 \%$ liver homogenate [tissue weight $(\mathrm{mg})$ : saline $(\mu \mathrm{L})=1: 9$ ] was used for the determination of the levels of MDA according to the protocols of a commercially available kit (Nanjing Jian Cheng Bioengineering Institute, Nanjing, China). After centrifugation at $3000 \times g$ for $15 \mathrm{~min}$ at $4^{\circ} \mathrm{C}(2-16 \mathrm{PK}$, SIGMA, Germany), the supernatants were collected to detect the content of MDA. This assay is based on the reaction of MDA with thiobarbituric acid (TBA). The procedure was performed as previously described ${ }^{[24]}$.

\section{Antioxidant enzymes activity in liver tissues}

A 10\% liver homogenate was used for the determination of the levels of SOD, CAT, and GPx activities in liver tissues. The levels were detected colorimetrically with UV-visible spectrophotometer using commercial kits (Nanjing Jian Cheng Bioengineering Institute, Nanjing, China) according to the manufacturer's protocol as previously described ${ }^{[24]}$.

\section{Preparation of nuclear protein fractionation}

Nuclear protein fractionation was prepared from rat liver tissue using the nuclear-cytosol extraction kit (Applygen Technologies Inc, Beijing, China) according to the manufacturer's instructions. Cut-up tissue was washed with PBS twice and treated with cell lysis buffer. Tissue was homogenized for 20-40 strokes and nuclei were visualized under a microscope. After centrifugation, the nuclear pellet was washed and lysed with nuclear lysis reagent. After centrifugation, the cleared supernatant was used as the nuclear protein extract. The protein concentrations of each of the nuclear lysates were measured and all concentrations were adjusted to be the same. After mixing with $4 \times$ sample buffer containing $\beta$-mercaptoethanol, the samples were heat-denatured at $90^{\circ} \mathrm{C}$ for $10 \mathrm{~min}$.

\section{Western blotting analysis}

Total protein samples were prepared according to a standard protocol. The total protein was used for the detection of a-SMA, SOD, HO-1, and NQO1. The protein levels were determined using a BCA assay kit (Applygen Technologies Inc, Beijing, China). Proteins were separated by SDS-polyacrylamide gel, transferred to a PVDF membrane (Millipore, MA, USA), and blocked with 5\% BSA in Tris-buffered saline containing $0.5 \%$ Tween 20 . Target proteins were detected by corresponding primary antibodies, and subsequently by horseradish peroxidase-conjugated secondary antibodies. Protein bands were visualized using chemiluminescence reagent (Applygen Technologies Inc, Beijing, China). Equivalent loading was confirmed using an antibody against $\beta$-actin or Histone H3 (for nuclein Nrf2 protein). The variation in the density of bands was expressed as fold changes compared to the control in the blot after normalization to $\beta$-actin or Histone H3.

\section{MTT assay}

The HSCs were isolated from male Wistar rats (normal rats). The isolation and culture of HSCs was carried out as previously described ${ }^{[21]}$. HSCs were seeded in a 96-well plate at an initial density of $2 \times 10^{5}$ cells $/ \mathrm{mL}$. After $24 \mathrm{~h}$, the cells were treated with control $(0.1 \% \mathrm{DMSO})$ or $\mathrm{CCl}_{4}(10 \mathrm{mmol} / \mathrm{L})$ and $\operatorname{Rg} 1\left(10^{-8}, 10^{-7}\right.$, and $\left.10^{-6} \mathrm{~mol} / \mathrm{L}\right)$ solutions for $24 \mathrm{~h}$. Following treatment, the cells were incubated with $5 \mathrm{mg} / \mathrm{mL}$ MTT tetrazolium $(10 \mu \mathrm{L} /$ well $)$ for $4 \mathrm{~h}$ at $37^{\circ} \mathrm{C}$. The reaction was terminated by the addition of $100 \mu \mathrm{L}$ DMSO. The absorbance of the dissolved formazan grains within the cells was measured at $570 \mathrm{~nm}$ using a microplate reader (SpectraMax-190, Molecular Device, USA). 


\section{Transient transfection with Nrf2 small interfering RNA}

HSCs were plated at a density of $2 \times 10^{5}$ cells $/ \mathrm{mL}$, grown for $24 \mathrm{~h}$, and transfected with $100 \mathrm{nmol} / \mathrm{L}$ Nrf2 siRNA (sc-37030; Santa Cruz) or control siRNA (sc-37007; Santa Cruz) using Lipofectamine 2000 reagent (Invitrogen) according to the manufacturer's instructions. After $48 \mathrm{~h}$ of transfection with Nrf2 siRNA, the cells were either treated with $\mathrm{Rg} 1$ alone or $\mathrm{CCl}_{4}$ and Rg1.

\section{Determination of MDA, GPX, PCIII, HA, and $\alpha$-SMA levels in cultured HSCs}

For the measurement of MDA, GPX, PCIII, HA, and a-SMA levels, HSCs were seeded in 6-well plates. Cells were treated with $10^{-6} \mathrm{~mol} / \mathrm{L} \mathrm{Rg} 1$ and $\mathrm{CCl}_{4}(10 \mathrm{mmol} / \mathrm{L})$ or DMSO for $24 \mathrm{~h}$ after control or Nrf2 siRNA transfection for $48 \mathrm{~h}$; nonsiRNA groups were cultured for $48 \mathrm{~h}$ and then treated with $10^{-6} \mathrm{~mol} / \mathrm{L} \mathrm{Rg} 1$ and $\mathrm{CCl}_{4}(10 \mathrm{mmol} / \mathrm{L})$ or DMSO for $24 \mathrm{~h}$. The cells were then harvested for Western blot analysis of a-SMA and the cell culture supernatant was assayed for the by commercially available kit (Nanjing Jiancheng Bioengineering Institute, Nanjing, China) according to the manufacturer's instructions.

\section{Statistical analysis}

Results are expressed as the mean \pm SD. SPSS13.0 statistical software was used for statistical analysis. Statistical evaluation was performed using one-way analysis of variance (ANOVA) followed by a Tukey test. The results of histopathological scoring system were analyzed with SPSS 13.0 using a nonparametric ranking analysis (Kruskal-Wallis test). Statistical significance was set at $P<0.05$.

\section{Results}

Rg1 alters serum biochemical parameters

The increase of ALT, AST, LDH, and ALP in the serum demonstrates the damage to the liver ${ }^{[25]}$. To evaluate the degree of liver damage, the serum levels of several functional liver enzymes were determined. Compared with the control group, the serum levels of ALT, AST, LDH, and ALP in the HF rats were profoundly increased $(P<0.01, P<0.01, P<0.01$, and $P<0.01$, respectively, Table 1$)$. However, the abnormal serum enzyme levels were significantly reversed by $\operatorname{Rg} 1$ in a dosedependent manner, especially for the $20 \mathrm{mg}$ and $40 \mathrm{mg}$ groups (ALT, $P<0.01$ and $P<0.01$; AST, $P<0.01$ and $P<0.01$; LDH,
$P<0.01$ and $P<0.01 ;$ ALP, $P<0.05$ and $P<0.01$, Table 1$).$

\section{Rg1 ameliorates liver pathology}

To determine the protective effects of $\mathrm{Rg} 1$ against $\mathrm{CCl}_{4}{ }^{-}$ induced injury, we conducted histological examination of the extent of hepatic injury. According to microscopic examination, the administration of $\operatorname{Rg} 1$ alleviates severe hepatic lesions induced by alcohol and $\mathrm{CCl}_{4}$. Control rats had no pathological changes in either the lateral or median lobes of the liver (Figure 1A). Rats in the untreated fibrosis group had degenerative changes in the liver: centrilobular necrosis including ballooning of hepatocytes, deposition of lipid droplets in hepatocytes and infiltration of inflammatory cells, as well as collagen deposition $^{[17]}$. In rats in the $\mathrm{Rg} 110 \mathrm{mg} / \mathrm{kg}$ treated group, severe hepatocyte necrosis and ballooning degeneration were observed, as well as numerous inflammatory cells around the necrotic tissue (Figure 1D). Moderate hydropic degeneration of hepatocytes was shown in Rg1 $20 \mathrm{mg} / \mathrm{kg}$ treated group. In the $\mathrm{Rg} 140 \mathrm{mg} / \mathrm{kg}$ treated group, hepatocyte necrosis nearly disappeared (Figure 1F), showing a significant reduction in necrosis and hydropic degeneration. The inflammation score of each group was evaluated. As shown in Figure 1G, the inflammation score was $0.18 \pm 0.01$ in the control group, while in the $\mathrm{CCl}_{4}$ group, the inflammation score was markedly increased $(3.17 \pm 0.32, P<0.01)$. In contrast, compared with the untreated fibrosis group, treatment with $\operatorname{Rg} 1(10,20$, and $40 \mathrm{mg} / \mathrm{kg}$ ) significantly reduced the increased inflammation scores $(2.55 \pm 0.33,2.05 \pm 0.19$, and 1.62 $\pm 0.50 ; P<0.05, P<0.01$, and $P<0.01$, respectively). The balloon degeneration score (Figure $1 \mathrm{H})$ was also significantly reduced by $\mathrm{Rg} 1(20 \mathrm{mg}, 1.95 \pm 0.20$ and $40 \mathrm{mg}, 1.45 \pm 0.18 ; P<0.01$, and $P<0.01$, respectively) compared with rats in the untreated fibrosis group $(2.53 \pm 0.19)$.

\section{Rg1 ameliorates hepatic fibrosis}

Hepatic fibrosis was evaluated by Masson's trichrome staining. According to microscopic examinations, obvious bridging fibrosis was observed in the livers of untreated rats, masses of collagen deposition surrounded the portal area, and the divided liver fibrosis formation staggered and formed a large number of false lobules (Figure 2B). Rg1 significantly alleviated the extent of hepatic fibrosis (Figure 2D-2F). In the $\operatorname{Rg} 120 \mathrm{mg} / \mathrm{kg}$ group (Figure 2E), liver fibrosis was mildly diminished, and merely disappeared in the $40 \mathrm{mg} / \mathrm{kg}$ group (Figure 2F). Further analysis showed that (Figure 2G) the

Table 1. Serum parameters in control rats and $\mathrm{CCl}_{4}$ rats receiving Rg1, bicyclol, or vehicle (DDW) treatment. Data are presented as mean \pm SD. ${ }^{\circ} P<0.01$ compared with control. ${ }^{\mathrm{e}} \mathrm{P}<0.05,{ }^{\mathrm{f}} P<0.01$ compared with $\mathrm{CCl}_{4}$ alone.

\begin{tabular}{|c|c|c|c|c|}
\hline Groups & $\operatorname{ALT}(U / L)$ & AST (U/L) & LDH (U/L) & $\operatorname{ALP}(U / L)$ \\
\hline Control $(n=6)$ & $27.3 \pm 2.3$ & $145.3 \pm 18.8$ & $363.0 \pm 70.5$ & $149.5 \pm 15.8$ \\
\hline $\mathrm{CCl}_{4}(n=10)$ & $439.2 \pm 97.1^{\mathrm{C}}$ & $780.9 \pm 134.8^{c}$ & $847.8 \pm 125.9^{c}$ & $454.7 \pm 44.1^{\mathrm{c}}$ \\
\hline $\mathrm{CCl}_{4}+\mathrm{Rg} 110 \mathrm{mg}(n=10)$ & $355.9 \pm 75.5$ & $588.3 \pm 79.4$ & $555.3 \pm 93.4^{e}$ & $403.6 \pm 49.4$ \\
\hline $\mathrm{CCl}_{4}+\mathrm{Rg} 120 \mathrm{mg}(n=9)$ & $178.5 \pm 23.8^{f}$ & $398.9 \pm 63.9^{f}$ & $459.3 \pm 88.4^{f}$ & $324.8 \pm 51.3^{\mathrm{e}}$ \\
\hline $\mathrm{CCl}_{4}+\mathrm{Rg} 140 \mathrm{mg}(n=10)$ & $159.6 \pm 23.6^{f}$ & $295.1 \pm 36.2^{f}$ & $378.4 \pm 39.3^{f}$ & $290.4 \pm 37.5^{f}$ \\
\hline
\end{tabular}



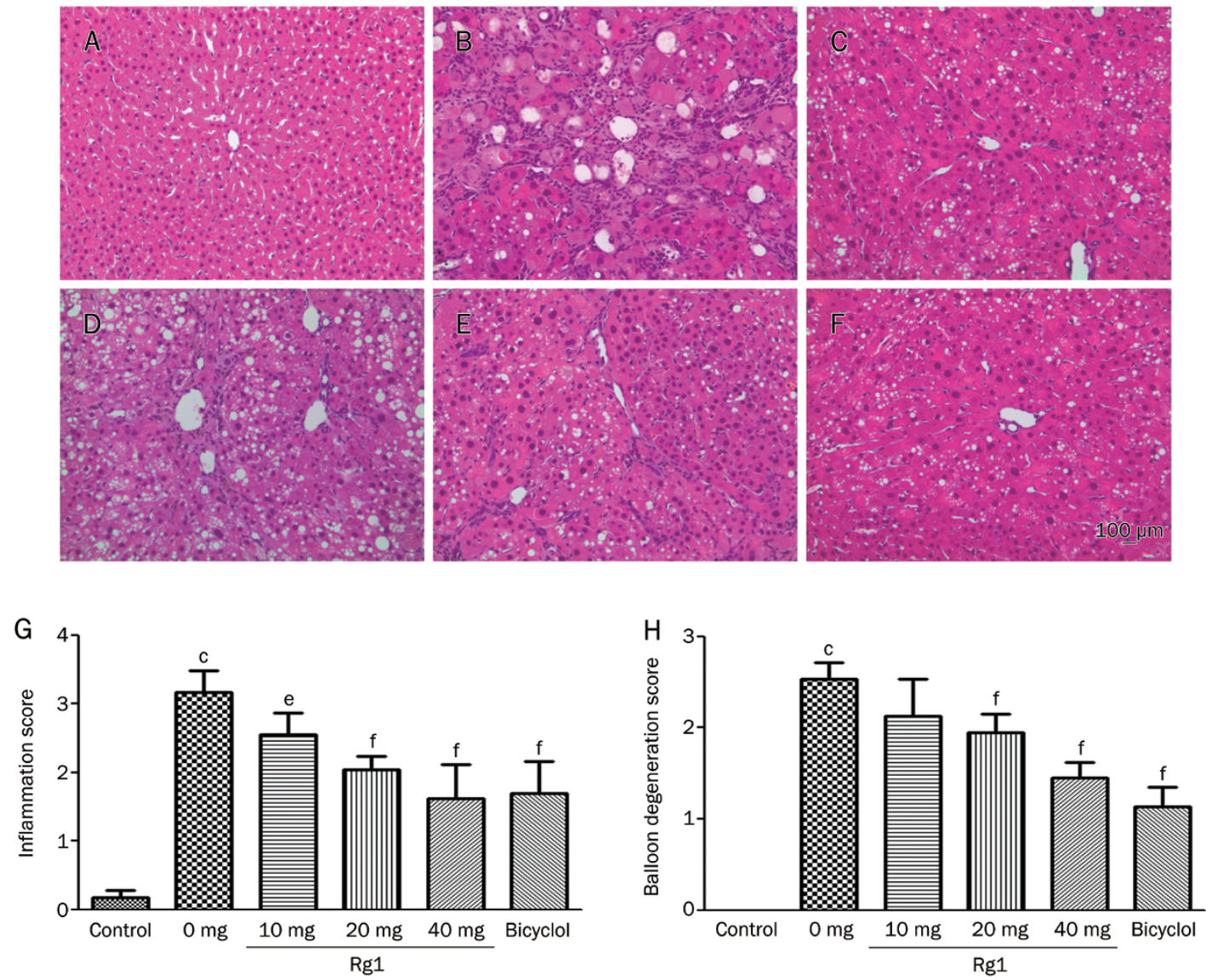

Figure 1. Effects of Rg1 on liver histology following $\mathrm{CCl}_{4}$ treatment. Rats were subcutaneously injected with $\mathrm{CCl}_{4}(0.2 \mathrm{~mL} / \mathrm{kg} \mathrm{BW,} \mathrm{twice} \mathrm{per} \mathrm{week)}$ for 8 weeks, and Rg1 and bicyclol were administered at the last two weeks (once a day). Representative photomicrographs of liver histology (H \& $\mathrm{E}$,

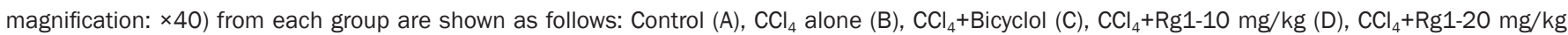
(E) and $\mathrm{CCl}_{4}+\mathrm{Rg} 1-40 \mathrm{mg} / \mathrm{kg}(\mathrm{F})$. Scale bar, $100 \mu \mathrm{m}$. The inflammatory score $(\mathrm{G})$ and balloon degeneration score $(\mathrm{H})$ were evaluated in ten randomly selected fields from each slide at a magnification of $\times 200$. All data were expressed as mean $\pm \mathrm{SD}$ of six animals. ${ }^{\mathrm{c}} P<0.01 \mathrm{vs}$ control. ${ }^{\mathrm{f}} P<0.01 \mathrm{vs} \mathrm{CCl}{ }_{4}$ alone.

fibrosis score was $0.30 \pm 0.11$ in the control group, and the score was markedly increased $(2.88 \pm 0.43, P<0.01)$ in the $\mathrm{CCl}_{4}$ group. Rats that were treated with $\mathrm{Rg} 1$ (20 and $40 \mathrm{mg} / \mathrm{kg}$ ) had significantly decreased fibrosis scores compared with the model group (2.17 \pm 0.31 and $2.00 \pm 0.30 ; P<0.05$ and $P<0.01$. Figure $2 \mathrm{G})$.

The level of hydroxyproline was $70.2 \pm 19.5 \mu \mathrm{g} / \mathrm{g}$ liver in the control group. In the $\mathrm{CCl}_{4}$ group, hydroxyproline content was markedly increased to 4.7 times that of the control group $(P<0.01)$. In contrast, treatment with Rg1 significantly reduced the increase in hydroxyproline content at 10,20 , and 40 $\mathrm{mg} / \mathrm{kg}(224.5 \pm 47.2,170.0 \pm 59.4,118.4 \pm 36.3 \mu \mathrm{g} / \mathrm{g}$ liver, each $P<0.01$; Figure 2H).

\section{Rg1 attenuates HSCs activation}

The protective effect of Rg1 in hepatic fibrosis is associated with the inhibition of HSC activation, which was determined by the inhibition of a-SMA ${ }^{+}$myofibroblast transition. Almost no expression of a-SMA was observed in the control rat livers (Figure 3A). Many a-SMA positive cells appear in untreated fibrotic liver and the positive areas are connected, dividing the liver into many annular lobules (Figure 3B). Rg1 reduced the a-SMA positive area in a dose-dependent manner (Figure 3D-3F). Much of the a-SMA expression remained evident in the Rg1-10 mg group, spreading from the portal area and linking positive areas together, occasionally forming false lobules (Figure 3D). Most of the a-SMA positive areas in the Rg1 20 mg group concentrated around the portal area, with a rare false flocculus structure. In the Rg1-40 mg group, almost all of the a-SMA-positive areas concentrated around the portal area with a shorter distance and a smaller area, and no false flocculus structures were observed. a-SMA positive area analysis showed that rats administered with 20 and $40 \mathrm{mg} / \mathrm{kg}$ Rg1 significantly block the a-SMA ${ }^{+}$cell accumulation $(6.33 \% \pm 2.08 \%$ and $4.21 \% \pm 1.97 \% ; P<0.05, P<0.01)$ compared with the control group $(9.26 \% \pm 2.28 \%, P<0.01$ vs control group. Figure $3 G)$.

Western blot analysis showed a similar trend as the a-SMApositive area analysis, revealing that the a-SMA levels were 50 times greater in $\mathrm{CCl}_{4}$-treated rats than in control rats. $\mathrm{CCl}_{4^{-}}$ treated rats receiving $\operatorname{Rg} 1(10,20$, and $40 \mathrm{mg} / \mathrm{kg}$ ) had signifi- 

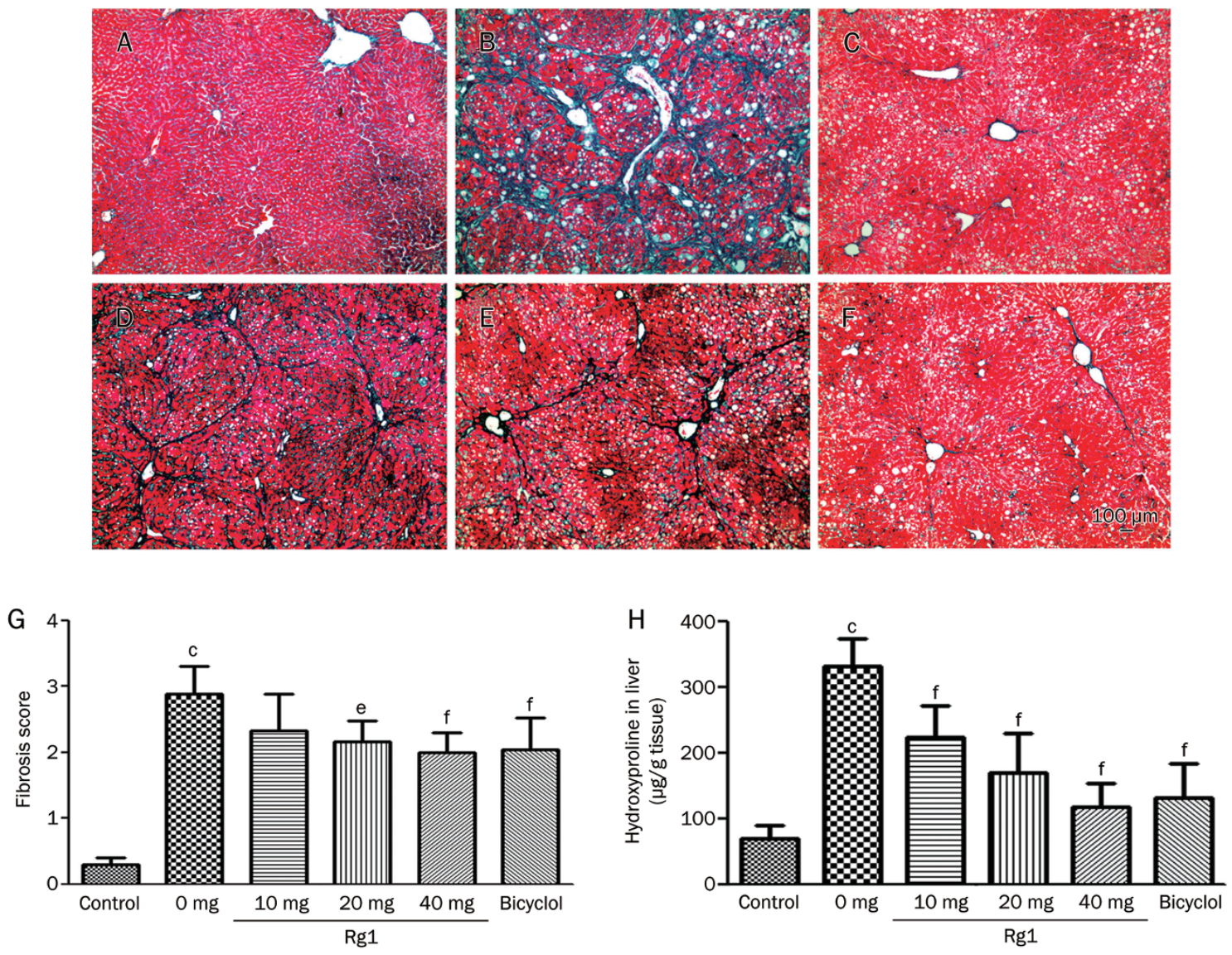

Figure 2. Effects of Rg1 on $\mathrm{CCl}_{4}$-induced hepatic fibrogenesis. Hepatic fibrosis was detected by Masson's trichromic staining. Representative photomicrographs of liver histology from each group are shown as follows: Control (A), $\mathrm{CCl}_{4}$ alone (B), $\mathrm{CCl}_{4}+\mathrm{Bicyclol}_{(\mathrm{C}), \mathrm{CCl}}+\mathrm{Rg} 1-10 \mathrm{mg} / \mathrm{kg}(\mathrm{D})$, $\mathrm{CCl}_{4}+\operatorname{Rg} 1-20 \mathrm{mg} / \mathrm{kg}(\mathrm{E})$ and $\mathrm{CCl}_{4}+\operatorname{Rg} 1-40 \mathrm{mg} / \mathrm{kg}(\mathrm{F})$. Original magnification: $\times 40$. Scale bar, $100 \mu \mathrm{m}$. The fibrosis score $(\mathrm{G})$ was evaluated in ten randomly selected fields from each slide at a magnification of $\times 200$. (H) The content of hydroxyproline in liver tissues. All data were expressed as means \pm SD of six animals. ${ }^{c} P<0.01$ vs control. ${ }^{f} P<0.01$ vs $\mathrm{CCl}_{4}$ alone.

cantly decreased a-SMA levels $(P<0.05, P<0.01$, and $P<0.01$, respectively, Figure $3 \mathrm{H}$ ).

\section{Effect of Rg1 on CYP2E1 mRNA and ADH activity in liver}

CYP2E1 is the most important enzyme of the liver cytochrome P450 system related to alcohol metabolism. Activity of ADH directly reflects the ability to eliminate alcohol. In the present study, we measured the CYP2E1 mRNA level and ADH activity in liver tissues. The average daily ethanol intake of the rats was $3.8-5.6 \mathrm{~g} / \mathrm{kg}$ during the modeling period. There was no significant difference among the ethanol water groups (Figure 4A). Compared with the control group, the level of CYP2E1 mRNA in the alcohol-only group and Rg1 groups showed no significant difference (Figure 4B). There was also no distinct difference observed on the ADH activity among these groups (Figure 4C).

Rg1 decreased lipid peroxidation and modified antioxidant enzyme activity

The levels of MDA were monitored to evaluate the effect of $\mathrm{Rg} 1$ treatment on alcohol- and $\mathrm{CCl}_{4}$-induced liver lipid peroxi- dation. A significant increase of MDA showed that oxidative damage was induced in the untreated fibrosis group $(8.61 \pm 0.94$ $\mathrm{nmol} / \mathrm{mg}$ protein, $P<0.001$, Figure $5 \mathrm{~A}$ ). Treatment with $\mathrm{Rg} 1$ $(10,20$, and $40 \mathrm{mg} / \mathrm{kg})$ significantly decreases the lipid peroxidation compared with the model group $(7.14 \pm 0.65,6.61 \pm 0.41$, and $6.30 \pm 0.35 \mathrm{nmol} / \mathrm{mg}$ protein; $P<0.05, P<0.01$ and $P<0.001$, respectively. Figure 5A).

SOD, GSH-Px, and CAT play pivotal roles in the scavenging of free radicals and the prevention of liver damage caused by ROS. The activities of these antioxidant enzymes were measured to evaluate the relationship between the antifibrotic and antioxidant effect of Rg1. As shown in Figure 5B-5D, these antioxidant enzymes are significantly modified in untreated fibrosis rats (CAT, $16.8 \pm 7.1 \mathrm{U} / \mathrm{mg}$ protein, $P<0.01$; GSH-Px, $1187 \pm 152 \mathrm{U}, P<0.01$; SOD, $372 \pm 42 \mathrm{U} / \mathrm{g}$ tissue, $P<0.05)$. Both the CAT and GSH-Px activities of the untreated fibrosis group are lower than that of the control group (mentioned above), and the activities in the rats treated with $\operatorname{Rg} 1$ were higher than those of the model group (CAT: $20 \mathrm{mg}, 28.7 \pm 4.5 \mathrm{U} / \mathrm{mg}$ protein, $P<0.05 ; 40 \mathrm{mg}, 39.2 \pm 3.2 \mathrm{U} / \mathrm{mg}$ protein, $P<0.01$. GSH-Px: $20 \mathrm{mg}, 2070 \pm 94 \mathrm{U}, P<0.01 ; 40 \mathrm{mg}, 2356 \pm 177 \mathrm{U}, P<0.01$. Figure 

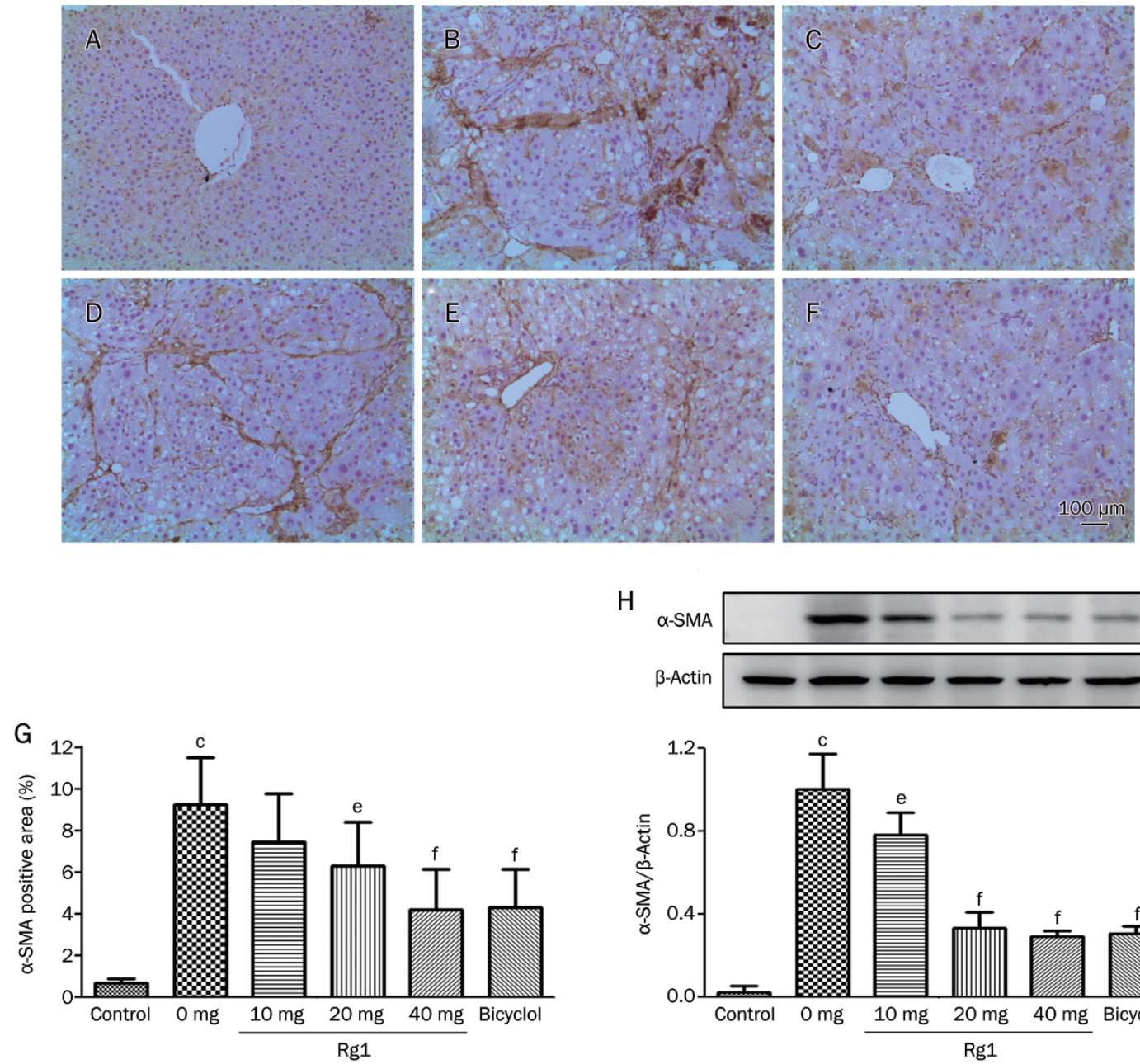

$\mathrm{H}$
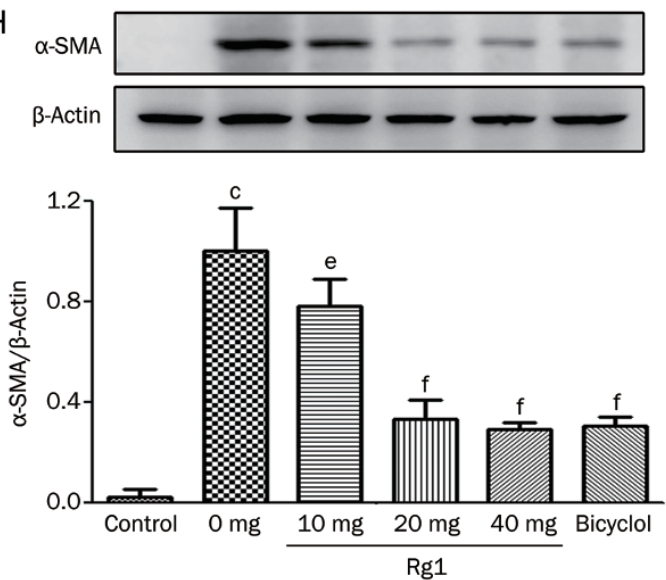

Figure 3. Effects of Rg1 on $\mathrm{CCl}_{4}$-induced expression of hepatic $\alpha$-SMA. Representative photomicrographs of liver histology from each group are shown as follows: Control (A), $\mathrm{CCl}_{4}$ alone (B), $\mathrm{CCl}_{4}+$ Bicyclol (C), $\mathrm{CCl}_{4}+\mathrm{Rg} 1-10 \mathrm{mg} / \mathrm{kg}(\mathrm{D}), \mathrm{CCl}_{4}+\mathrm{Rg} 1-20 \mathrm{mg} / \mathrm{kg}(\mathrm{E})$ and CCl $+\mathrm{Rg} 1-40 \mathrm{mg} / \mathrm{kg}(\mathrm{F})$. Original magnification: $\times 100$. Scale bar, $100 \mu \mathrm{m}$. (G) Morphometrical analysis was performed for evaluating percentages of $\alpha$-SMA-positive area in 12 random fields per section of six animals. $(\mathrm{H})$ Western bloting analysis of $\alpha$-SMA in liver tissue. Representative blots were from three independent experiments. The data were expressed as means \pm SD. ${ }^{c} P<0.01$ vs control. ${ }^{e} P<0.05,{ }^{f} P<0.01$ vs $\mathrm{CCl}_{4}$ alone.

5B and 5C). Interestingly, the SOD activity of the model group is higher than that of the control group $(293 \pm 46 \mathrm{U} / \mathrm{g}$ tissue, $P<0.05$. Figure 5D), while that of the Rg1-treated groups were even higher than the untreated fibrosis group $(20 \mathrm{mg}, 461 \pm 40$ $\mathrm{U} / \mathrm{g}$ tissue, $P<0.05 ; 40 \mathrm{mg}, 473 \pm 26 \mathrm{U} / \mathrm{g}$ tissue, $P<0.01$. Figure $5 \mathrm{D})$. This result was confirmed by Western blot detection of SOD in the liver (Figure 5E).

\section{Rg1 activates the Nrf2 pathway}

Nrf2 plays an important role in the activation of antioxidant enzymes by regulating their transcription ${ }^{[26]}$. As shown in Figure 6A, the nuclein Nrf2 protein of the untreated fibrosis rats showed a slight higher expression compared to the control group but no statistical significance. Compared with the control rats, the rats given with $\operatorname{Rg} 1(10,20$, and $40 \mathrm{mg})$ had markedly increased levels of Nrf2 $(P<0.01, P<0.01$, and $P<0.01$. Figure 6A). When compared to the untreated fibrosis rats, the Rg1 groups (10, 20, and $40 \mathrm{mg}$ ) had significantly increased lev- els of Nrf2 $(P<0.05, P<0.01$, and $P<0.01$. Figure 6A). The result implies that Rg1 promotes the nuclear translocation of the Nrf2 protein, which leads to recovery from alcohol-mediated acceleration of $\mathrm{CCl}_{4}$-induced liver fibrosis. The expression of Ho-1 and Nqo1 show the same tendency: Ho-1 was dramatically increased in three of the Rg1 groups $(P<0.01$, Figure 6A), as was Nqo1 ( $P<0.05$, Figure 6A), in comparison to the expression in the control group.

We also measured the level of nuclein Nrf2 protein in rats treated with $\operatorname{Rg} 1$ (40 mg/kg). Interestingly, we found that Nrf2 protein was significantly increased in the Rg1 administration group compared to the saline group $(P<0.05$, Figure 6B).

\section{Nrf2 plays a key role in the anti-fibrosis mechanism of Rg1}

The $\mathrm{CCl}_{4}$-induced HSC proliferation was inhibited by Rg1 $\left(10^{-7}, 10^{-6} \mathrm{~mol} / \mathrm{L}\right)$ compared with that of the $\mathrm{CCl}_{4}$ only group $(P<0.05, P<0.01$, respectively; Figure $7 \mathrm{~A})$. As $10^{-6} \mathrm{~mol} / \mathrm{L}$ of Rg1 showed a better and more stable effect, this concentration 

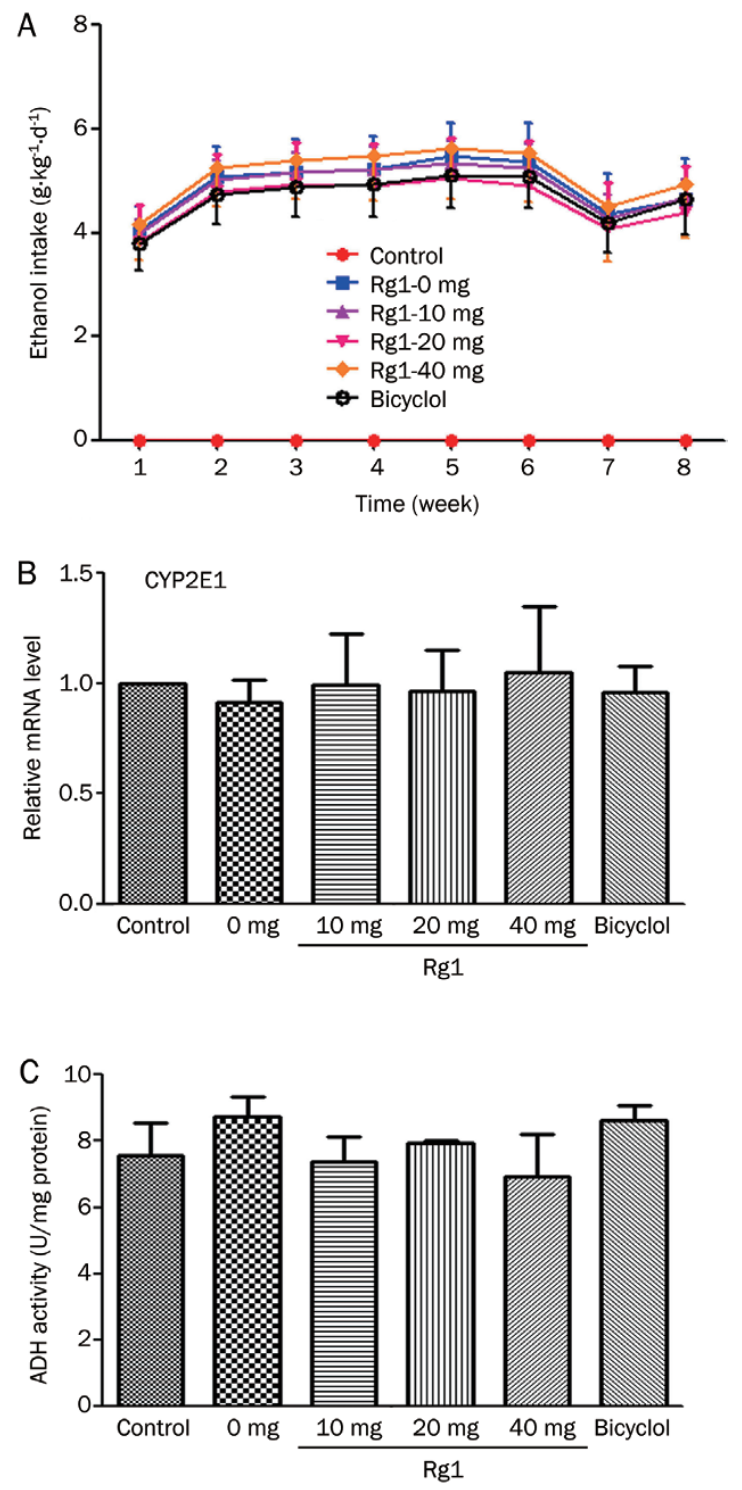

Figure 4. Effects of Rg1 on the hepatic CYP2E1 mRNA levels and ADH activity in rats with ethanol exposure. Rats were treated with $6 \%(\mathrm{v} / \mathrm{v})$ alcohol water for 8 weeks, and Rg1 and Bicyclol were administrated the last two weeks (once a day). (A) The ethanol intake was record during the modeling period. (B) CYP2E1 mRNA levels were quantified with GAPDH as an internal control. Quantitative analysis was taken three independent qPCR analyses. (C) ADH activity in rat liver with ethanol exposure. $n=6$. Data are presented as mean \pm SD.

was chosen for the following study.

To determine the role of Rg1 on Nrf2 activation and to verify the inhibition efficiency of Nrf2 siRNA, the Nrf2 protein was measured by Western blot. The results indicated that Nrf2 siRNA significantly diminished Rg1-induced Nrf2 translocation (Figure 7B).

The content of MDA and GPX in the supernatant fluid of cultured HSCs was evaluated. Rg1 significantly decreased the MDA level $(P<0.01)$ and increased the GPX level $(P<0.01)$ compared with $\mathrm{CCl}_{4}$-only group. This protective effect can be partially reversed by Nrf2 siRNA (Figure 7C, 7D).

PCIII and HA are important markers of hepatic fibrosis. a-SMA is the marker of HSCs activation. The level of PCIII and HA in the supernatant fluid of cultured HSCs were both significantly decreased in Rg1-treated group $(P<0.01$ and $P<0.01$, respectively) compared with $\mathrm{CCl}_{4}$-only group. And in Nrf2 siRNA group, there was no significant difference of the level of anti-fibrotic markers (PCIII and HA) compared to the $\mathrm{CCl}_{4}$-only group (Figure 7E, 7F). The expression of a-SMA protein showed a similar tendency as PCIII and HA (Figure 7G). This indicates that $\mathrm{Rg} 1$ can inhibit the $\mathrm{CCl}_{4}$-induced activation of HSCs, and Nrf2 siRNA can partially reverse the effect.

\section{Discussion}

Hepatic fibrosis has received global attention because of the high morbidity, severe economy burdens and psychological pressure that it causes. However, a lack of effective drugs and therapeutic strategies render it difficult to treat. Therefore, it is imperative to find new drugs to treat hepatic fibrosis. As the main collagen producing cells in the chronic liver injury ${ }^{[27]}$, hepatic stellate cells are considered the key therapeutic target for hepatic fibrosis ${ }^{[5]}$. Oxidative stress represents a direct or indirect pro-fibrogenic stimulus for HSC activation ${ }^{[28-30]}$. In the search for therapeutic strategies for hepatic fibrosis, many antioxidants show promising results ${ }^{[24,30-36]}$, including ginseng extracts $^{[22,37]}$. However, there are few reports that have evaluated the effects of $\operatorname{Rg} 1$ on hepatic fibrosis by inhibiting oxidative stress ${ }^{[21]}$. Thus, the aim of our present investigation was to explore the antifibrotic capacity of Rg1 by attenuating oxidative stress and the underlying mechanisms.

Alcohol-related hepatic fibrosis is clinically common, but experimental models of alcoholic hepatitis that effectively mimic the human pathological findings require further exploration ${ }^{[38]}$. Existing animal models are limited because of the long modeling period and low success rate. $\mathrm{CCl}_{4}$ has been widely used to induce chronic liver damage, especially in models of hepatic fibrosis and primary hepatic cirrhosis ${ }^{[39]}$. ROS play an important role in the activation of HSC and collagen accumulation in alcohol-related hepatic fibrosis ${ }^{[38,40-44]}$. It is now generally accepted that liver fibrosis produced by $\mathrm{CCl}_{4}$ is induced by oxidative stress. Chronic alcohol intake markedly upregulates the activity of CYP2E1, which is a major isozyme involved in catalyzing $\mathrm{CCl}_{4}$ into the trichloromethyl free radical $\left(\cdot \mathrm{CCl}_{3}\right)^{[9,10]}$. In the present study, a shortened modeling period with a high success rate were achieved by the complex modeling method. All of the animals in the model group developed severe liver fibrosis and few animals died. The pathological outcomes were similar to those of a recent study ${ }^{[45]}$, but our method is shorter in duration.

Ginseng extracts have been reported to exert protective effects, in in vitro studies as well as in various animal and clinical models, in models of liver injury induced by a variety of hepatotoxins, including $\mathrm{CCl}_{4}$ and alcohol ${ }^{[17,19,22,37,46]}$. However, research on the effect of Rg1 on liver fibrosis is limited ${ }^{[21]}$. Increases in serum AST, ALT, LDH, and ALP levels have been 

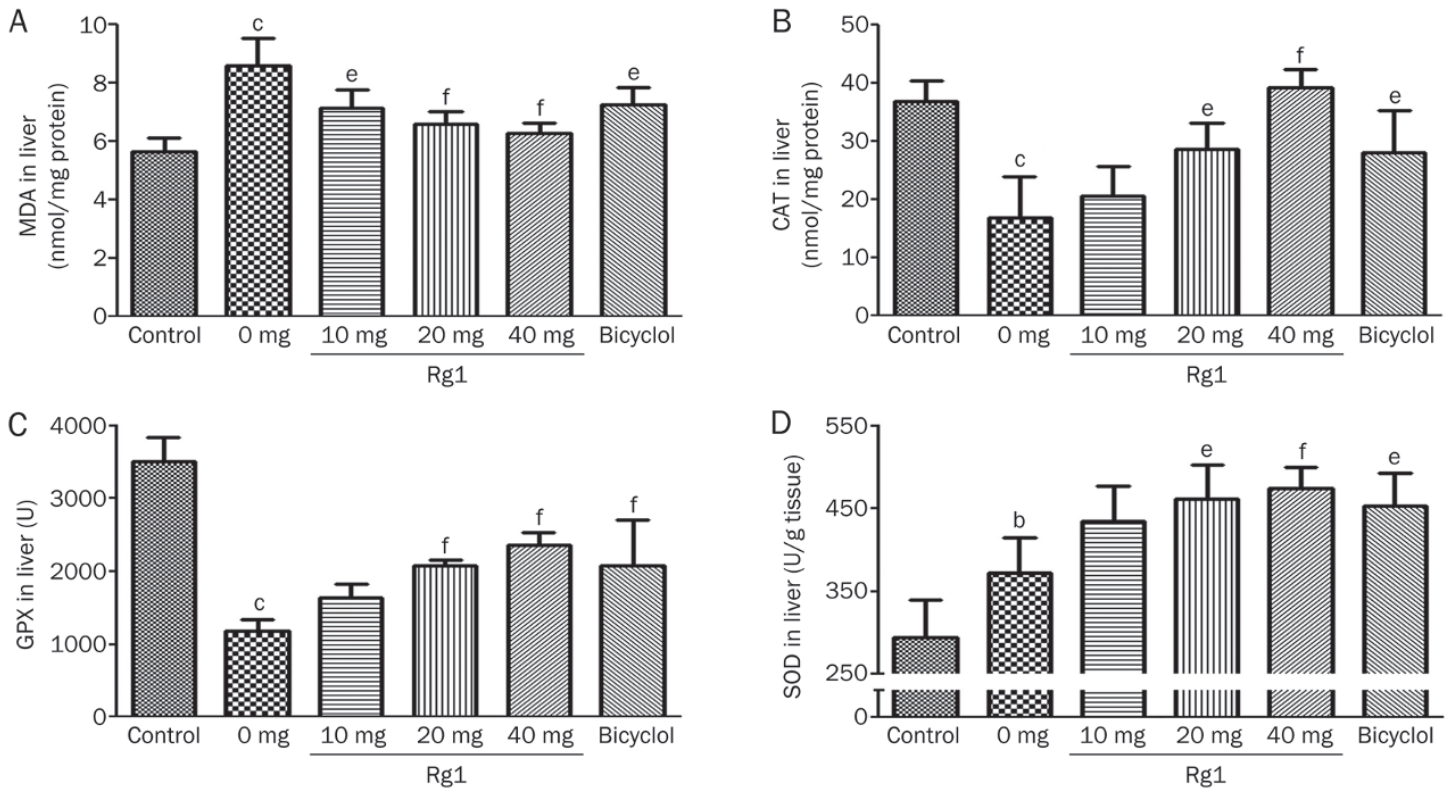

$E$
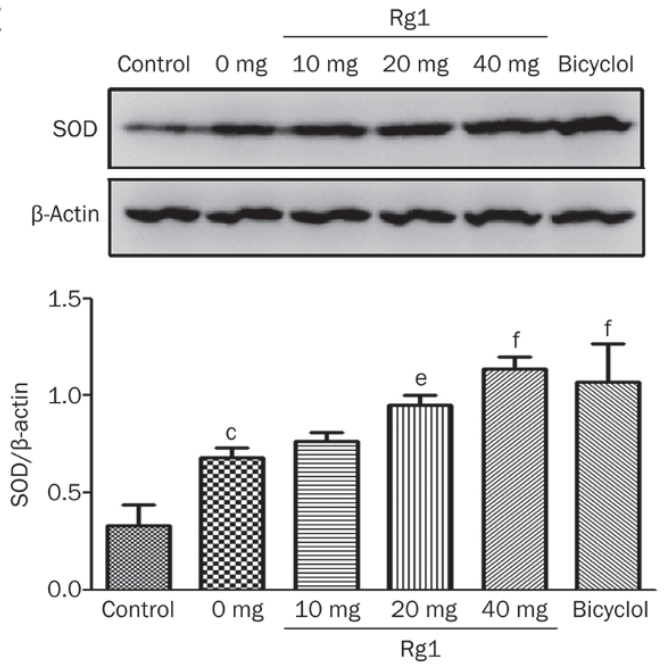

Figure 5. Effect of Rg1 on $\mathrm{CCl}_{4}$-induced changes in the levels of hepatic antioxidant enzyme activities and lipid peroxidation. The activities of antioxidant enzyme and level of lipid peroxidation in the liver $(n=6)$ were determined and the data are shown as follows: MDA levels (A), CAT activities (B), GPX activities (C), SOD activities (D), Western bloting analysis of SOD protein (E). Representative blots were from three independent experiments. The data were expressed as mean \pm SD. ${ }^{\mathrm{b}} P<0.05,{ }^{\mathrm{c}} P<0.01$ vs control. ${ }^{\mathrm{e}} P<0.05,{ }^{\mathrm{f}} P<0.01$ vs $\mathrm{CCl}_{4}$ alone.

used as biomarkers of damaged structural integrity of the liver. In Geng's study ${ }^{[21]}$, the increased levels of serum AST, ALT, and ALP induced by thioacetamide were reduced by Rg1. In our study, treatment with Rg1 inhibited hepatotoxininduced liver damage in a dose-dependent manner, as evidenced by decreased AST, ALT, ALP, and LDH levels.

In our study, the level of CYP2E1 mRNA in the untreated fibrosis group showed no difference compared with the control group. This finding is consistent with a previous study ${ }^{[47]}$ that showed mRNA expression levels were unchanged in a 2-month ethanol intragastric feeding model. There are also studies that have reported that moderate ethanol intake may not induce CYP2E $1^{[48,49]}$. These studies ${ }^{[48,49]}$ concluded that moderate ethanol intake exacerbated liver fibrosis, but did not affect the hepatotoxicity of $\mathrm{CCl}_{4}$. Taken together, these data demonstrated that the $6 \%$ alcohol water in our study may not induce CYP2E1 mRNA expression, while it may exacerbate liver fibrosis in combination with $\mathrm{CCl}_{4}$. The $\mathrm{ADH}$ activity in the liver was not different among these groups, suggesting that $\operatorname{Rg} 1$ has no effect on ADH.

Activated HSCs are the major source of $\mathrm{ECM}^{[50-52]}$. Increased expression of a-SMA, a marker of transdifferentiation, is one of the major phenotypic changes that activated HSCs display ${ }^{[53-55]}$. In the present study, compared to the $\mathrm{CCl}_{4}$ group, Rg1 decreased the number of a-SMA positive cells in the liver. Additionally, this result was confirmed by Western blot analysis of a-SMA protein. The results indicated that Rg1 inhibited transactivation of HSCs in injured liver. Together with the results of Masson's trichrome staining, these results imply that the antifibrotic effects of Rg1 may result from inhibition of transdifferentiation of HSCs.

The antioxidant defense systems include SOD-, CAT-, and GSH-related enzymes (GPx, GR, and GST) ${ }^{[56]}$. A previous study ${ }^{[18]}$ found that $\operatorname{Rg} 1$ is capable of buffering excessive free radicals and attenuating the oxidative damage in liver in an exhaustive exercise model. In our study, alcohol and $\mathrm{CCl}_{4}$ induced significant modifications to these antioxidant enzymes. We found that the activities of CAT and GSH-Px 
A
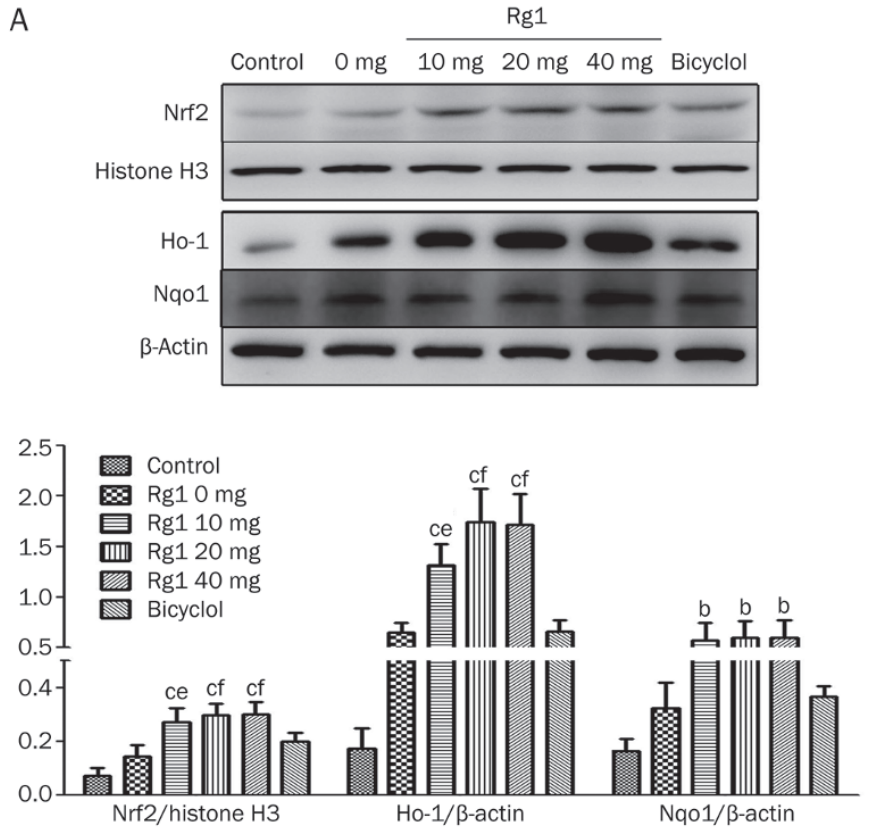

B
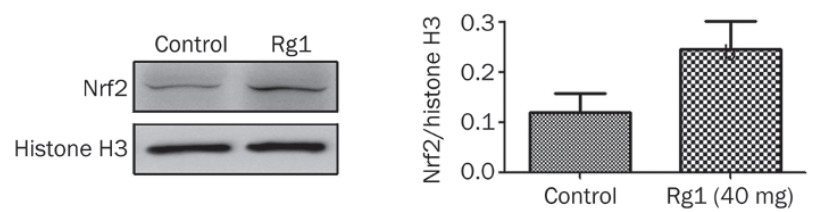

Figure 6. Effects of Rg1 on expression of Nrf2 pathway. (A) Rats were subcutaneously injected with $\mathrm{CCl}_{4}(0.2 \mathrm{~mL} / \mathrm{kg} \mathrm{BW}$, twice per week) for 8 weeks, and Rg1 and bicyclol were administered at the last two weeks (once a day). (B) Rats were administered with saline and Rg1 (40 mg/kg) for two weeks (once a day). Western bloting analysis with the indicated antibodies. Histone $\mathrm{H} 3$ or $\beta$-Actin was used as an invariant control for equal loading. Representative blots were from three independent experiments. Data were expressed as mean $\pm S D$. Statistical evaluation was performed using $t$-test. Nucleus Nrf2 (A, B) and total Ho-1 and Nqo1 (A) were detected and analyzed. ${ }^{b} P<0.05,{ }^{\mathrm{C}} P<0.01$ vs control. ${ }^{\mathrm{e}} P<0.05$,

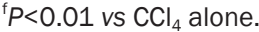

were lower in the model group than in the control group, and Rg1 was capable of elevating the activities of these antioxidant enzymes. Interestingly, in contrast with some previous reports, the SOD activity in the model group was higher than in the control group. It appears that SOD was spontaneously activated to protect the liver from oxidative damage and that Rg1 could further enhance the SOD activity. As a downstream effector of the Nrf2 pathway, SOD activity is closely related to the level of Nrf2 in the nucleus. Given that the nuclear Nrf2 level increased in the model livers (though without significant differences), the elevation of SOD activity is expected. This finding is consistent with a study ${ }^{[57]}$ that investigated the neuroprotective effect of melatonin in a rotenone model of PD. It appears that Rg1 relieves liver injuries by up-regulating the activities of CAT, SOD, and GSH-Px to scavenge the free radicals induced by alcohol and $\mathrm{CCl}_{4}$.
The up-regulation of many antioxidant enzymes, or the inhibition of lipid peroxidation in the liver is mediated by Nrf2. Upon exposure to oxidative or electrophilic stress, Nrf2 dissociates from Keap1 and translocates to the nucleus, where it binds to the ARE and leads to an array of transcriptional regulatory proteins ${ }^{[58-59]}$, including Ho-1, Nqo1, CAT, SOD, and GSH-Px ${ }^{[60-64]}$. In our study, Western blot analysis showed that the enhanced expression of Nrf2 in the nuclear transplantation by $\operatorname{Rg} 1$ is consistent with the increased activities of antioxidant enzymes by Rg1 (Figure 5, 6A). This result demonstrates that the Nrf2 pathway contributes to the anti-fibrotic effect of Rg1. To our surprise, the rats treated with Rg1 also showed increased expression of nuclear Nrf2 (Figure 6B). To validate the key role of Nrf2 in the anti-fibrotic mechanism of Rg1, siRNA-induced knock down of Nrf2 in HSCs was conducted. Not surprisingly, the protective effect of $\mathrm{Rg} 1$ in $\mathrm{CCl}_{4}$-treated HSCs was reversed in the Nrf2 siRNA group. Taken together, these results suggest that Rg1 is an Nrf2 activator and that Nrf2 plays a key role in the anti-fibrotic mechanism of Rg1.

Some of the Nrf2 activators have progressed to clinical trials for treatment of conditions such as skin cancer, multiple sclerosis and chronic kidney disease ${ }^{[65]}$. Nrf2 is considered to be involved in protection against ethanol-induced oxidative stress $^{[65-67]}$. Evidence from studies in which Nrf2 has been knocked down in cells, and in studies that used Nrf2-null mice ${ }^{[6]]}$, show that Nrf2 plays a protective role against ethanolinduced liver damage. As a potential activator of Nrf2, Rg1 increases the activity of antioxidant enzymes such as Ho-1 and CAT. Therefore, Rg1-induced activation of Nrf2 renders the liver more resistant to the oxidative stress induced by alcohol.

Nrf2 activation is generally considered to have a beneficial effect $^{[68]}$, especially in liver disease ${ }^{[65,69]}$. In Nrf2 knockout mice, increased death and delayed proliferation of hepatocytes were observed ${ }^{[70]}$. After long-term $\mathrm{CCl}_{4}$ treatment, liver fibrosis was strongly aggravated in the Nrf2 knockout mice, and inflammation was enhanced ${ }^{[13]}$. A recent publication reported that there was no beneficial effect of Nrf2 activation on $\mathrm{CCl}_{4^{-}}$ induced liver injury and fibrosis in caNrf2-transgenic mice ${ }^{[7]}$. This result is interesting and very different from the conclusions of many other publications. Most studies, either by pharmacological activation or in Nrf2 gene knockout models, has shown that Nrf2 activation was beneficial to liver injury and fibrosis. However, in this paper, the author genetically activated Nrf2 only in hepatocytes, although inflammatory cells are not as protected as the hepatocytes, which may have contributed to the observations. Pharmacological activation not only targets hepatocytes but also all of the inflammatory cells involved in mediating $\mathrm{CCl}_{4}$-induced damage. Thus, cells other than hepatocytes could also be involved in mediating a protective effect. Additionally, pharmacological activation of Nrf2 also targets many different pathways, such as NF-kB inhibition, possibly contributing to a protective effect in cells other than hepatocytes. Similarly, the Nrf2 knockout mouse studies used mice with a global Nrf2 knockout, meaning that the effect could also be mediated by inflammatory cells.

Both alcohol and $\mathrm{CCl}_{4}$ contribute to the oxidative stress 
A

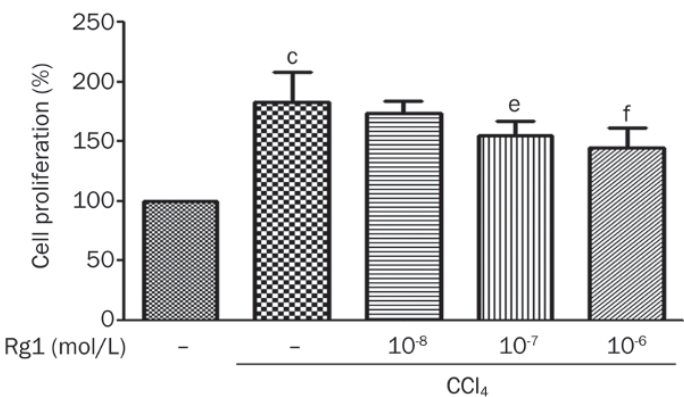

C

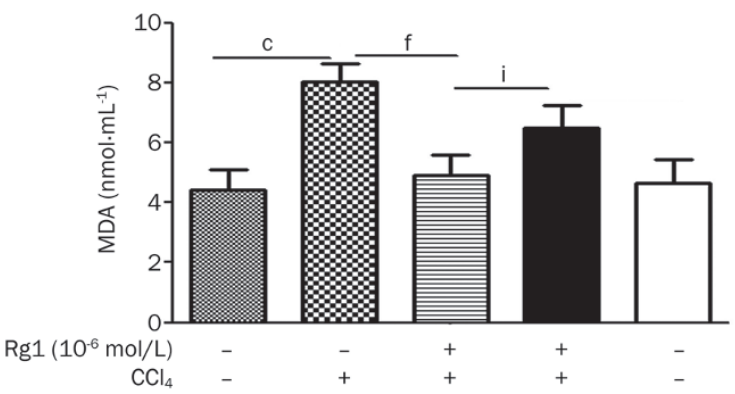

E

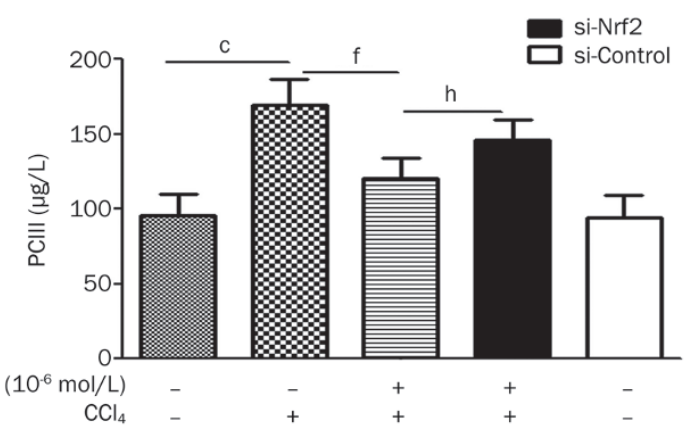

G
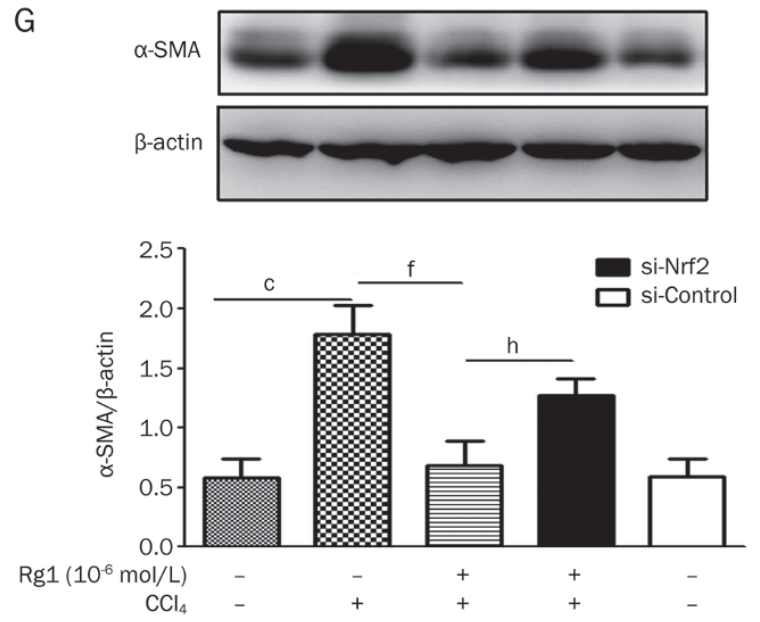

B
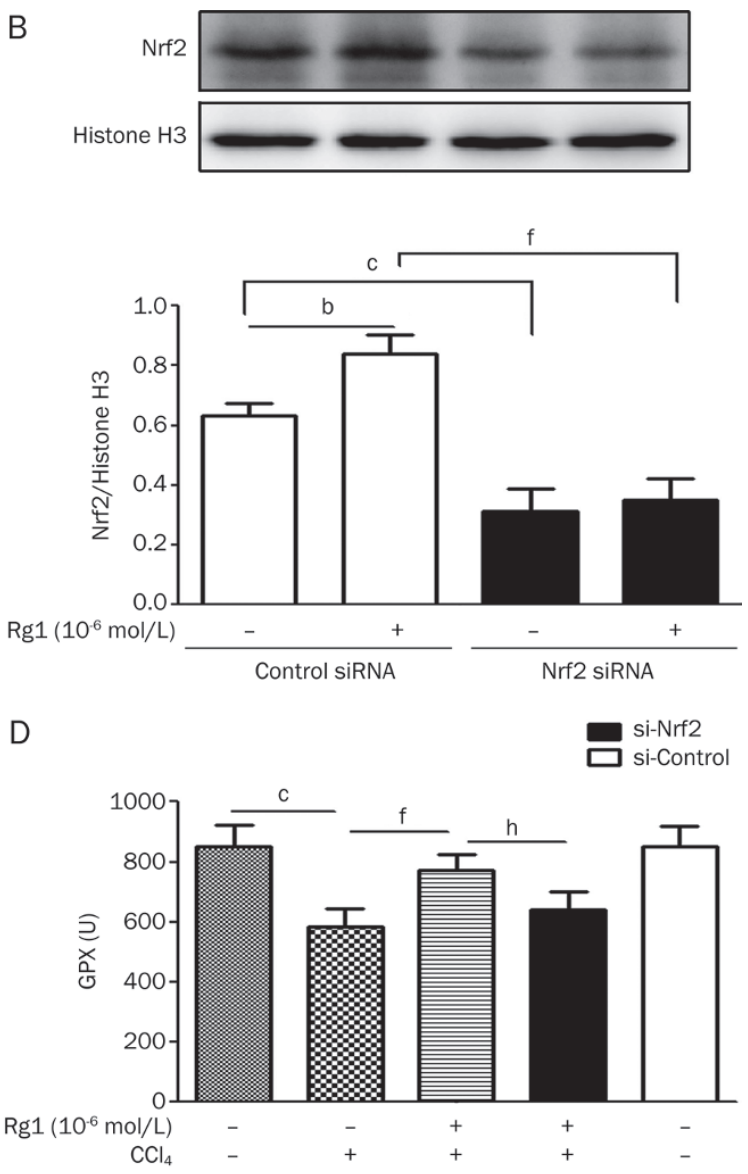

$\mathrm{F}$

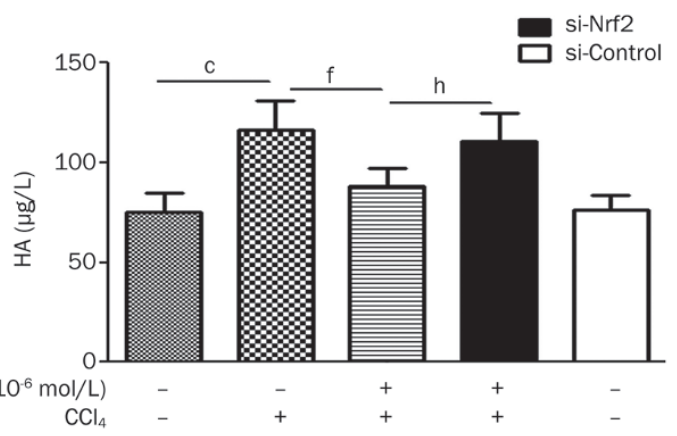

Figure 7. Nrf2 playing a key role in the mechanism of anti-hepatic fibrosis by Rg1. (A) Effect of Rg1 on prolieration in HSCs. Primary HSCs were incubated with $\mathrm{Rg} 1$ and $\mathrm{CCl}_{4}(10 \mathrm{mmol} / \mathrm{L})$ for $24 \mathrm{~h}$. Data represent mean \pm SD of 6 separate experiments. (B) Nrf2 siRNA inhibits Rg1induced translocation of Nrf2. Cells were treated with $1 \mu \mathrm{mol} / \mathrm{L}$ Rg1 for $24 \mathrm{~h}$ after control or Nrf2 siRNA transfection for $48 \mathrm{~h}$. Protein expression of Nrf2 was detected by Western blotting. Representative blots were from three independent experiments. The content of MDA (C), GPX (D), PCIII (E), and HA (F) in the cell cultured supernatant and the $\alpha$-SMA expression in HSCs $(\mathrm{G})$. Cells were treated with $1 \mu \mathrm{mol} / \mathrm{L} \mathrm{Rg1} \mathrm{and} \mathrm{CCl}_{4}(10$ $\mathrm{mmol} / \mathrm{L}$ ) or DMSO for $24 \mathrm{~h}$ after control or Nrf2 siRNA transfection for $48 \mathrm{~h}$; non-siRNA groups were cultured for $48 \mathrm{~h}$ and then treated with 1 $\mu \mathrm{mol} / \mathrm{L} \mathrm{Rg} 1$ and $\mathrm{CCl}_{4}(10 \mathrm{mmol} / \mathrm{L})$ or DMSO for $24 \mathrm{~h}$. The data were expressed as mean \pm SD. $n=6$. Statistical evaluation was performed using $t$-test. ${ }^{\mathrm{b}} P<0.05,{ }^{\mathrm{c}} P<0.01$ vs control. ${ }^{\mathrm{e}} P<0.05,{ }^{\mathrm{f}} P<0.01$ vs $\mathrm{CCl}_{4}$ alone. ${ }^{\mathrm{h}} P<0.05,{ }^{\mathrm{i}} P<0.01$ vs $\mathrm{Rg} 1+\mathrm{CCl}_{4}$ group. 
in the liver that is relevant to HSC activation in the present study. Augmented antioxidant defense systems, including Ho-1, Nqo1, CAT, SOD, and GSH-Px, restrain the HSC activation, and therefore suppress liver fibrosis. The levels of these antioxidant enzymes are consistent with the nuclear Nrf2 in the Rg1 groups. It is clear that further research is required to determine the exact role of Rg1 on the activation of Nrf2.

In summary, the present study demonstrated that $\operatorname{Rg} 1$ has a protective effect on ethanol-mediated acceleration of $\mathrm{CCl}_{4}$ induced liver fibrosis in rats. Treatment with Rg1 blocked the expression of a-SMA. Rg1 is capable of upregulating the ability of antioxidases and down-regulating the level of lipid peroxidation. We demonstrated that Rg1 may be an Nrf2 activator. The protective effect of Rg1 may be related to its ability to promote Nrf2 nuclear translocation and enhance the expression of Nrf2 target genes.

\section{Acknowledgements}

This work was supported by National Natural Science Foundation of China grants (№ 81274122, 81373510, 81273629, 81373998 ) and by the Beijing Natural Science Foundation (№ 7131013), Research Fund for the Doctoral Program of Higher Education of China (№ 2012110613001), National 863 Program of China (No 2012AA020303), PCSIRT (№ IRT1007), National Key Sci-Tech Major Special Item (No 2012ZX09301002-004, 2012ZX09103101-006), and Beijing Key Laboratory of New Drug Mechanisms and Pharmacological Evaluation Study (№ BZ0150).

\section{Author contribution}

Jian-ping LI, Yan GAO, Zhao ZHANG, and Cong-yuan XIA performed most of the experiments. Xiu-yun SONG, Zheng MOU, Xiao-feng GUO, and Wen-bin HE assisted in the experiments. Jian-ping LI analyzed data. Jian-ping LI and Shi-feng CHU prepared the manuscript. Nai-hong CHEN and Shi-feng CHU designed the study.

\section{References}

1 Xu R, Zhang Z, Wang FS. Liver fibrosis: mechanisms of immunemediated liver injury. Cell Mol Immunol 2012; 9: 296-301.

2 Davis GL, Alter MJ, El-Serag H, Poynard T, Jennings LW. Aging of hepatitis $\mathrm{C}$ virus (HCV)-infected persons in the United States: a multiple cohort model of HCV prevalence and disease progression. Gastroenterology 2010; 138: 513-21, 21 e1-6.

3 Mitchell AE, Colvin HM, Palmer Beasley R. Institute of medicine recommendations for the prevention and control of hepatitis $\mathrm{B}$ and $\mathrm{C}$. Hepatology 2010; 51: 729-33.

4 Lim YS, Kim WR. The global impact of hepatic fibrosis and end-stage liver disease. Clin Liver Dis 2008; 12: 733-46.

5 Friedman SL. Mechanisms of disease: mechanisms of hepatic fibrosis and therapeutic implications. Nat Clin Pract Gastroenterol Hepatol 2004; 1: 98-105.

6 Poli G. Pathogenesis of liver brosis: role of oxidative stress. Mol Aspects Med 2000; 21: 49-98.

7 Zhu W, Fung PC. The roles played by crucial free radicals like lipid free radicals, nitric oxide, and enzymes NOS and NADPH in $\mathrm{CCl}_{4}$-induced acute liver injury of mice. Free Radic Biol Med 2000; 29: 870-80.
8 Yang YS1, Ahn TH, Lee JC, Moon CJ, Kim SH, Jun W, et al. Protective effects of pycnogenol on carbon tetrachloride-induced hepatotoxicity in sprague-dawley rats. Food Chem Toxicol 2008; 46: 380-7.

9 Weber LW, Boll M, Stampfl A. Hepatotoxicity and mechanism of action of haloalkanes: carbon tetrachloride as a toxicological model. Crit Rev Toxicol 2003; 33: 105-36.

10 SLATER TF. Free-radical mechanisms in tissue injury. Biochem J 1984; 222: 1-15.

11 Wu S, Yue Y, Tian H, Li Z, Li X, He W, et al. Carthamus red from Carthamus tinctorius $L$ exerts antioxidant and hepatoprotective effect against $\mathrm{CCl}_{4}$-induced liver damage in rats via the Nrf2 pathway. J Ethnopharmacol 2013; 148: 570-8.

12 Jiang T, Huang Z, Chan JY, Zhang DD. Nrf2 protects against As(III)induced damage in mouse liver and bladder. Toxicol Appl Pharmacol 2009; 240: 8-14.

13 Xu W, Hellerbrand C, Kohler UA, Bugnon P, Kan YW, Werner S, et al. The Nrf2 transcription factor protects from toxin-induced liver injury and fibrosis. Lab Invest 2008; 88: 1068-78.

14 Du J, Cheng B, Zhu X, Ling C. Ginsenoside Rg1, a novel glucocorticoid receptor agonist of plant origin, maintains glucocorticoid efficacy with reduced side effects. J Immunol 2011; 187: 942-50.

15 Im DS, Nah SY. Yin and Yang of ginseng pharmacology: ginsenosides vs gintonin. Acta Pharmacol Sin 2013; 34: 1367-73.

16 Radad K, Gille G, Moldzio R, Saito H, Rausch WD. Ginsenosides Rb1 and Rg1 effects on mesencephalic dopaminergic cells stressed with glutamate. Brain Res 2004; 1021: 41-53.

17 Ki SH, Yang JH, Ku SK, Kim SC, Kim YW, Cho IJ. Red ginseng extract protects against carbon tetrachloride-induced liver fibrosis. J Ginseng Res 2013; 37: 45-53.

18 Korivi M, Hou CW, Huang CY, Lee SD, Hsu MF, Yu SH, et al. Ginsenoside-Rg1 protects the liver against exhaustive exerciseinduced oxidative stress in rats. Evid Based Complement Alternat Med 2012; 2012: 932165.

19 Nguyen HT, Uto T, Morinaga O, Kim YH, Shoyama Y. Pharmacological effects of ginseng on liver functions and diseases: a minireview. Evid Based Complement Alternat Med 2012; 2012: 173297.

20 Tsai KD1, Yang SM, Lee JC, Wong HY, Shih CM, Lin TH, et al. Panax notoginseng attenuates bleomycin-induced pulmonary fibrosis in mice. Evid Based Complement Alternat Med 2011; 2011: 404761.

21 Geng J, Peng W, Huang Y, Fan H, Li S. Ginsenoside-Rg1 from Panax notoginseng prevents hepatic fibrosis induced by thioacetamide in rats. Eur J Pharmacol 2010; 634: 162-9.

22 Park WH, Lee SK, Kim CH. A Korean herbal medicine, Panax notoginseng, prevents liver fibrosis and hepatic microvascular dysfunction in rats. Life Sci 2005; 76: 1675-90.

23 Thompson K, Maltby J, Fallowfield J, Mcaulay M, Millward-Sadler H, Shero N. Interleukin-10 expression and function in experimental murine liver inflammation and fibrosis. Hepatology 1998; 28: $1597-$ 606.

24 Chen S, Zou L, Li L, Tie W. The protective effect of glycyrrhetinic acid on carbon tetrachloride-induced chronic liver fibrosis in mice via upregulation of Nrf2. PloS One 2013; 8: e53662.

25 Rej R. Aspartate aminotransferase activity and isoenzyme proportions in human liver tissues. Clin Chem 1978; 24: 1971-9.

26 Hare MLC. Tyramine oxidase A new enzyme system in liver. Biochem J 1928; 22: 968-79.

27 Friedman SL. Stellate cell activation in alcoholic fibrosi - an overview. Alcohol Clin Exp Res 1999; 23: 904-10.

28 Hernandez-Gea V, Friedman SL. Pathogenesis of liver fibrosis. Annu Rev Pathol 2011; 6: 425-56.

29 Novo E, Parola M. Redox mechanisms in hepatic chronic wound 
healing and fibrogenesis. Fibrogen Tissue Repair 2008; 1: 1-58.

30 Zhang F, Ni C, Kong D, Zhang X, Zhu X, Chen L, et al. Ligustrazine attenuates oxidative stress-induced activation of hepatic stellate cells by interrupting platelet-derived growth factor-beta receptor-mediated ERK and p38 pathways. Toxicol Appl Pharmacol 2012; 265: 51-60.

31 Tsai MK, Lin YL, Huang YT. Effects of salvianolic acids on oxidative stress and hepatic fibrosis in rats. Toxicol Appl Pharmacol 2010; 242: 155-64.

32 Shaker ME, Zalata KR, Mehal WZ, Shiha GE, Ibrahim TM. Comparison of imatinib, nilotinib and silymarin in the treatment of carbon tetrachloride-induced hepatic oxidative stress, injury and fibrosis. Toxicol Appl Pharmacol 2011; 252: 165-75.

33 Pirinccioglu M, Kizil G, Kizil M, Kanay Z, Ketani A. The protective role of pomegranate juice against carbon tetrachloride-induced oxidative stress in rats. Toxicol Indust Health 2012.

34 Domitrovic R, Jakovac H, Marchesi VV, Blazekovic B. Resolution of liver fibrosis by isoquinoline alkaloid berberine in $\mathrm{CCl}_{4}$-intoxicated mice is mediated by suppression of oxidative stress and upregulation of MMP-2 expression. J Med Food 2013; 16: 518-28.

35 Nurrochmad A1, Margono SA, Sardjiman, Hakim AR, Ernawati, Kurniawati E, Fatmawati E. Hepatoprotective and antioxidant activity of pentagamavunon-0 against carbon tetrachloride-induced hepatic injury in rats. Asian Pacific J Trop Med 2013; 6: 438-42.

36 Ottu OJ, Atawodi SE, Onyike E. Antioxidant, hepatoprotective and hypolipidemic effects of methanolic root extract of Cassia singueana in rats following acute and chronic carbon tetrachloride intoxication. Asian Pacific J Trop Med 2013; 6: 609-15.

37 Bak MJ, Jun M, Jeong WS. Antioxidant and hepatoprotective effects of the red ginseng essential oil in $\mathrm{H}_{2} \mathrm{O}_{2}$-treated HepG2 cells and $\mathrm{CCl}_{4}$ treated mice. Int J Mol Sci 2012; 13: 2314-30.

38 Altamirano J, Bataller R. Alcoholic liver disease: pathogenesis and new targets for therapy. Nat Rev Gastroenterol Hepatol 2011; 8: 491-501.

39 Tuñón MJ. An overview of animal models for investigating the pathogenesis and therapeutic strategies in acute hepatic failure. World J Gastroenterol 2009; 15: 3086.

40 Arthur MJP, Iredale JP, Mann DA. Tissue inhibitors of metalloproteinases: role in liver fibrosis and alcoholic liver disease. Alcohol Clin Exp Res 1999; 23: 940-3.

41 Meagher EA, Barry OP, Burke A, Lucey MR, Lawson JA, Rokach J, et al. Alcohol-induced generation of lipid peroxidation products in humans. J Clin Invest 1999; 104: 805-13.

42 Houstis N, Rosen ED, Lander ES. Reactive oxygen species have a causal role in multiple forms of insulin resistance. Nature 2006; 440: 944-8.

43 Lieber CS, Weiss DG, Paronetto F. Value of fibrosis markers for staging liver fibrosis in patients with precirrhotic alcoholic liver disease. Alcohol Clin Exp Res 2008; 32: 1031-9.

44 Kluwe J, Pradere JP, Gwak GY, Mencin A, De Minicis S, Osterreicher $\mathrm{CH}$, et al. Modulation of hepatic fibrosis by C-Jun-N-terminal kinase inhibition. Gastroenterology 2010; 138: 347-59.

45 Wang JH, Choi MK, Shin JW, Hwang SY, Son CG. Antifibrotic effects of Artemisia capillaris and Artemisia iwayomogi in a carbon tetrachlorideinduced chronic hepatic fibrosis animal model. J Ethnopharmacol 2012; 140: 179-85.

46 El Denshary ES, Al-Gahazali MA, Mannaa FA, Salem HA, Hassan NS, Abdel-Wahhab MA. Dietary honey and ginseng protect against carbon tetrachloride-induced hepatonephrotoxicity in rats. Exp Toxicol Pathol 2012; 64: 753-60.

47 Gouillon ZQ, Miyamoto K, Donohue TM, Wan YJ, French BA, Nagao Y, et al. Role of CYP2E1 in the pathogenesis of alcoholic liver disease: modifications by CAMP and ubiquitin-proteasome pathway. Front Biosci 1999; 4: 16-25.

48 Chiang DJ, Roychowdhury S, Bush K, McMullen MR, Pisano S, Niese K, et al. Adenosine $2 \mathrm{~A}$ receptor antagonist prevented and reversed liver fibrosis in a mouse model of ethanol-exacerbated liver fibrosis. PloS One 2013; 8: e69114.

49 Roychowdhury S, Chiang DJ, Mandal P, McMullen MR, Liu X, Cohen $\mathrm{Jl}$, et al. Inhibition of apoptosis protects mice from ethanol-mediated acceleration of early markers of $\mathrm{CCl}_{4}$-induced fibrosis but not steatosis or inflammation. Alcohol Clin Exp Res 2012; 36: 1139-47.

50 Bataller R, Brenner DA. Liver fibrosis. J Clin Invest 2005; 115: 209 18.

51 Gressner AM, Weiskirchen R. Modern pathogenetic concepts of liver fibrosis suggest stellate cells and TGF-beta as major players and therapeutic targets. J Cell Mol Med 2006; 10: 76-99.

52 Friedman SL. Mechanisms of hepatic fibrogenesis. Gastroenterology 2008; 134: 1655-69.

53 Cho IJ, Kim YW, Han CY, Kim EH, Anderson RA, Lee YS, et al. E-cadherin antagonizes transforming growth factor beta1 gene induction in hepatic stellate cells by inhibiting RhoA-dependent Smad3 phosphorylation. Hepatology 2010; 52: 2053-64.

54 Hinz B, Phan SH, Thannickal VJ, Galli A, Bochaton-Piallat ML, Gabbiani G. The myofibroblast: one function, multiple origins. Am J Pathol 2007; 170: 1807-16.

55 Kang KW, Kim YG, Cho MK, Bae SK, Kim CW, Lee MG, et al. Oltipraz regenerates cirrhotic liver through CCAAT/enhancer binding proteinmediated stellate cell inactivation. FASEB J 2002; 16: 1988-90.

56 Xia D, Fan Y, Zhang P, Fu Y, Ju M, Zhang X. Protective effects of the flavonoid-rich fraction from Rhizomes of Smilax glabra Roxb on carbon tetrachloride-induced hepatotoxicity in rats. J Membr Biol 2013; 246: 479-85.

57 Saravanan KS, Sindhu KM, Mohanakumar KP. Melatonin protects against rotenone-induced oxidative stress in a hemiparkinsonian rat model. J Pineal Res 2007; 42: 247-53.

58 Itoh K, Tong KI, Yamamoto M. Molecular mechanism activating Nrf2Keap1 pathway in regulation of adaptive response to electrophiles. Free Radical Biol Med 2004; 36: 1208-13.

59 Kobayashi M, Yamamoto M. Molecular mechanisms activating the Nrf2-Keap1 pathway of antioxidant gene regulation. Antioxid Redox Signal 2005; 7: 385-94.

60 Bardag-Gorce F, Oliva J, Lin A, Li J, French BA, French SW. Proteasome inhibitor up-regulates liver antioxidative enzymes in rat model of alcoholic liver disease. Exp Mol Pathol 2011; 90: 123-30.

61 Farombi EO, Shrotriya S, Na HK, Kim SH, Surh YJ. Curcumin attenuates dimethylnitrosamine-induced liver injury in rats through Nrf2-mediated induction of heme oxygenase-1. Food Chem Toxicol 2008; 46: 1279-87.

62 Wartman MA. Constitutive and beta-naphthoflavone-induced expression of the human gamma-glutamylcysteine synthetase heavy subunit gene is regulated by a distal antioxidant response element/ TRE sequence. J Biol Chem 1997; 272: 7445-54.

63 Jeong WS, Jun M, Kong AN. Nrf2: A potential molecular target for cancer chemoprevention by natural compounds. Antioxid Redox Signal 2006; 8: 99-106.

64 Mann GE, Niehueser-Saran J, Watson A, Gao L, Ishii T, de Winter P, et al. Nrf2/ARE regulated antioxidant gene expression in endothelial and smooth muscle cells in oxidative stress: implications for atherosclerosis and preeclampsia. Acta Physiol Sin 2007; 59: 117-27.

65 Bataille AM, Manautou JE. Nrf2: a potential target for new therapeutics in liver disease. Clin Pharmacol Ther 2012; 92: 340-8.

66 Lamlé J1, Marhenke S, Borlak J, von Wasielewski R, Eriksson CJ, 
Geffers R, et al. Nuclear factor-eythroid 2-related factor 2 prevents alcohol-induced fulminant liver injury. Gastroenterology 2008; 134: 1159-68.e2.

67 Wu KC, Cui JY, Klaassen CD. Beneficial role of Nrf2 in regulating NADPH generation and consumption. Toxicol Sci 2011; 123: 590600.

68 Collins AR1, Gupte AA, Ji R, Ramirez MR, Minze LJ, Liu JZ, et al. Myeloid deletion of nuclear factor erythroid 2-related factor 2 increases atherosclerosis and liver injury. Arterioscler Thromb Vasc Biol 2012: 2839-46.
69 Shin SM, Yang JH, Ki SH. Role of the Nrf2-ARE pathway in liver diseases. Oxidat Med Cell Longevity 2013; 2013: 763257.

70 Beyer TA, Xu W, Teupser D, auf dem Keller U, Bugnon P, Hildt E, et al. Impaired liver regeneration in Nrf2 knockout mice: role of ROSmediated insulin/IGF-1 resistance. EMBO J 2008; 27: 212-23.

71 Köhler UA1, Kurinna S, Schwitter D, Marti A, Schäfer M, Hellerbrand C, et al. Activated Nrf2 impairs liver regeneration in mice by activation of genes involved in cell cycle control and apoptosis. Hepatology 2013 Dec 6. doi: 10.1002/hep.26964. 